\title{
A fauna de peixes na bacia do Rio Peruípe, extremo Sul da Bahia
}

\author{
Luisa Maria Sarmento-Soares ${ }^{1,3}$, Rosana Mazzoni ${ }^{1}$ \& Ronaldo Fernando Martins-Pinheiro ${ }^{2}$
}

Biota Neotropica v7 (n3) - http://www.biotaneotropica.org.br/v7n3/pt/abstract?inventory+bn02107032007

\author{
Recebido em 16/06/07 \\ Versão reformulada recebida em 05/09/07 \\ Publicado em 23/09/07
}

\author{
${ }^{1}$ Laboratório de Ecologia de Peixes, Deptartamento de Ecologia, \\ Instituto de Biologia Roberto Alcantara Gomes, Universidade do Estado do Rio de Janeiro - UERJ, \\ Av. São Francisco Xavier, 524, sala 225, Maracanã, CEP 20550-013, Rio de Janeiro, RJ, Brazil \\ e-mail: biobahia@nossacasa.net,mazzoni@uerj.br,www.uerj.br \\ ${ }^{2}$ Projeto BIOBAHIA, Alto do Rio do peixe pequeno, quadra 2, lote 14, Cumuruxatiba, CEP 45983-000 \\ Prado,BA, Brasil,e-mail:pinheiro.martins@gmail.com,www.nossacasa.net/biobahia \\ ${ }^{3}$ Autor para correspondência: Luisa Maria Sarmento Soares, e-mail: biobahia@nossacasa.net
}

\begin{abstract}
Sarmento-Soares, L.M., Mazzoni, R. \& Martins-Pinheiro, R.F. The fish fauna of the Rio Peruípe, extreme southern of Bahia state. Biota Neotrop. Sep/Dez 2007 vol. 7, no. 3 http://www.biotaneotropica.org.br/v7n3/pt/ abstract?inventory+bn02107032007. ISSN 1676-0603.

Hydrological richness on extreme southern Bahia contrasts with the poorly known freshwater fish fauna. It is surprising the presence of several species still undescribed. The present study is the first contribution dealing with the fish fauna of the local river basins. We herein investigate fish fauna of Rio Peruípe basin, a remarkably freshwater drainage, with a wide estuary. Eleven localities, geo-referred, were evaluated in streams and rivulets along that freshwater drainage. The employment of methodology for collecting the environmental data and the fishes made possible the description of each locality sampled, as well as the documentation of the taxonomic composition of the fish fauna. Illustrations of the collecting localities and of individuals of some representative species, in live coloration, are provided. There were found 26 species belonging to 12 families in 6 orders. Within the species sampled Trichomycterus pradensis Sarmento-Soares et al. (2005) and Microglanis pataxo Sarmento-Soares et al. (2006) were recently described as new. About 48.7\% of total amount of fishes caught belong to the order Siluriformes, $38.5 \%$ to Characiformes, $34.6 \%$ to Perciformes, $11.5 \%$ to Cyprinodontiformes, $7.7 \%$ to Gymnotiformes, $3.8 \%$ to Synbranchiformes, and 3.8\% to Pleuronectiformes. The most frequent species in terms of constancy of occurrence were Geophagus brasiliensis (present in $82 \%$ of sampled localities), Hoplias malabaricus (64\%), Astyanax cf. rivularis (55\%), Poecilia vivipara (55\%), Astyanax cf. lacustris (45\%) and Hyphessobrycon bifasciatus $(45 \%)$. Based on information about the fishes caught in each collecting locality there were estimated the richness, the diversity, the equitability and the dominance. The potential loss of microenvironments in some portions of rivers is pointed as a factor influencing on the occurrence and distribution of some species. The dominance of small sized fishes, not exceeding $150 \mathrm{~mm} \mathrm{CP}$, is associated to a high regional endemism.
\end{abstract}

Keywords: ichthyofauna, riachos, coastal "tabuleiros", northeastern, Brazil.

\section{Resumo}

Sarmento-Soares, L.M., Mazzoni, R. \& Martins-Pinheiro, R.F. A fauna de peixes na bacia do Rio Peruípe, extremo Sul da Bahia. Biota Neotrop. Sep/Dez 2007 vol. 7, no. 3 http://www.biotaneotropica.org.br/v7n3/pt/a bstract?inventory+bn02107032007. ISSN 1676-0603.

A riqueza hidrológica no Extremo Sul da Bahia é contrastante em relação à ainda pouco conhecida fauna de peixes. Impressiona a presença de diversas espécies ainda não descritas. O presente estudo é parte de uma série que pretende avaliar os sistemas hídricos do Extremo Sul da Bahia do ponto de vista da ictiofauna nas diversas bacias. Aqui são investigados os peixes da bacia do Rio Peruípe, um sistema ímpar de drenagem fluvial, com um amplo delta. Foram averiguados onze pontos georreferenciados em rios e riachos daquele sistema de drenagem. $\mathrm{O}$ uso de metodologia para coleta de dados ambientais e de peixes possibilitou descrever cada ambiente coletado bem como documentar a composição taxonômica da ictiofauna. São fornecidas ilustrações das localidades amostrais e de espécimes representativos de algumas das espécies coletadas, exibindo sua coloração em vida. No total foram verificadas 26 espécies pertencentes a 12 famílias em 6 ordens. Das espécies coletadas Trichomycterus pradensis Sarmento-Soares et al. (2005) e Microglanis pataxo Sarmento-Soares et al. (2006) foram recentemente descritas como novas. Aproximadamente 48,7\% do total de peixes na bacia pertencem à ordem Siluriformes, $38,5 \%$ a Characiformes, $34,6 \%$ a Perciformes, $11,5 \%$ a Cyprinodontiformes, $7,7 \%$ a Gymnotiformes, $3,8 \%$ a Synbranchiformes e 3,8\% a Pleuronectiformes. As espécies mais freqüentes em termos de constância de ocorrência foram Geophagus brasiliensis (presente em $82 \%$ das coletas), Hoplias malabaricus (64\%), Astyanax cf. rivularis (55\%), Poecilia vivipara (55\%), Astyanax cf. lacustris (45\%) e Hyphessobrycon bifasciatus (45\%). A partir das 
informações de captura dos peixes em cada ponto amostrado da bacia determinou-se a riqueza, a diversidade, a equitabilidade e a dominância. As condições ambientais nos trechos da bacia são apontadas como influências na ocorrência e distribuição das espécies. A predominância de peixes de pequeno porte, não ultrapassando $150 \mathrm{~mm} \mathrm{CP}$, é associada a um acentuado endemismo regional.

Palavras-chave: ictiofauna, riachos, tabuleiros costeiros, nordeste, Brasil.

\section{Introdução}

O Extremo Sul da Bahia corresponde a uma região de importância máxima quanto à biodiversidade por restarem manchas de floresta costeira atlântica onde a alteração ambiental é mínima. No sul da Bahia, estão concentradas as maiores reservas de Mata Atlântica do nordeste brasileiro. A pequena alteração antrópica sobre estas áreas ainda florestadas faz supor que sua composição ictiofaunística esteja próxima da original. A área drenada pela bacia hidrográfica do Rio Peruípe conta com a APA de Ponta da Baleia/Abrolhos (CRA 2002), localizada no terço inferior da bacia próximo ao delta. O delta do Rio Caravelas mantém ainda um nível relativamente alto de preservação, com uma extensa área de manguezais. No trecho médio as áreas já estão bem devastadas, ou ocupadas por plantações de eucalipto, mas ainda podemos encontrar matas ciliares em vários trechos dos rios. Já na parte alta, a devastação é completa, com muitos córregos retificados e com o desaparecimento quase total das matas ciliares. Apesar dos esforços para o estabelecimento de áreas a preservar, a destruição da biodiversidade na Floresta Atlântica no Extremo Sul da Bahia é dramática. O impacto da remoção da vegetação original representa um perigo para a sobrevivência da fauna nativa, com o risco de desaparecimento de espécies muito suscetíveis a alterações ambientais como no caso dos peixes que habitam poças temporárias na várzea de rios. É perfeitamente possível que ao longo dos pouco mais de 500 anos de descobrimento e colonização muita das espécies nativas de peixes da floresta Atlântica tenham se extinguido. O entendimento da ocupação no vale do Peruípe é importante na associação com a ictiofauna na bacia. As primeiras informações sobre as espécies de peixes de água doce no Rio Peruípe foram colhidas apenas ao final do século XX, já durante o processo de retirada das matas nativas da região. Alguns registros de espécies amostradas na bacia e/ou depositadas em coleções científicas aparecem em banco de dados e em relatório técnico. O Projeto BioBahia - "Diversidade, endemismo e análise biogeográfica de Siluriformes em sistemas hídricos pouco explorados no Extremo Sul da Bahia (Osteichthyes: Ostariophysi)", busca investigar os sistemas hídricos, de pequeno e grande porte, do extremo sul baiano e vem realizando um levantamento detalhado desta região. O presente trabalho tem como objetivo investigar a composição das espécies na bacia do Rio Peruípe avaliando sua distribuição espacial e endemismo.

\section{Material e Métodos}

\section{1. Área de estudo}

A região de Caravelas está historicamente ligada ao Descobrimento do Brasil. A passagem de viajantes pelo litoral de Caravelas foi marcada pela presença de Américo Vespúcio e Gonçalo Coelho, os primeiros portugueses a fazer um reconhecimento daquele trecho do litoral em 1503 (Albuquerque 1987, Dias 1923); além da passagem do Padre José de Anchieta, em 1553. Em sua passagem por Caravelas, em 1815, o príncipe Maximiliano Von Neuwied destacou a exuberância dos manguezais no delta do rio: "Entre Viçosa e Caravelas há um verdadeiro labirinto, formado por uma multidão de ilhas de mangues" (Wied-Neuwied 1940). Ainda no século XIX a região foi visitada pelo naturalista britânico Charles Darwin, em 1832 (Keynes 2004), que teve sua atenção voltada para o mar, em virtude da proximidade do arquipélago de Abrolhos, o maior conjunto de recifes de coral do Atlântico Sul. O desbravador mineiro Teófilo Otoni também passou pela região, em 1857, e veio a contribuir para integração do litoral com o interior (Chagas 1978). O vale do Rio Peruípe era dominado por matas e de difícil acesso. A Estrada de Ferro Bahia-Minas abriu o caminho ao litoral, atravessando a Serra dos Aimorés, em Minas Gerais até Caravelas, no litoral baiano, ao final do século XIX. A via de acesso facilitou a colonização da Serra dos Aimorés e a ocupação humana no terço superior do vale do Rio Peruípe (de Paula 2005). $\mathrm{O}$ avanço da exploração madeireira se deu no século $\mathrm{XX}$, entre as décadas de 60 e 80, quando foi removida grande parte da floresta nativa da região (Pinto 2004). O escoamento das madeiras nobres foi facilitado com a abertura da BR-101 no início da década de 70, e culminou com o corte de grande parte da mata que ainda havia no vale. A implantação de florestas de eucalipto para abastecer as indústrias de papel e celulose se deu apenas ao final do século XX (Pinto 2004).

A bacia do Peruípe apresenta um relevo pouco movimentado, caracterizado predominantemente pelos tipos Suave Ondulado e Plano (MMA/SRH 1997). Em direção a serra dos Aimorés as espessuras da série Barreiras diminuem gradativamente por se encontrarem em transição com as zonas de embasamento cristalino (idade précambriana), onde aparecem rochas de composição granítica. É a única área da bacia com relevo do tipo Forte Ondulado, onde está situada a maior elevação do vale: a Pedra do Lajedão (MMA/SRH 1997). A bacia do Rio Peruípe é geologicamente constituída por uma extensa cobertura sedimentar, de idades Terciária e Quaternária. Os sedimentos terciários são formados pela Série Barreiras, uma formação de sedimentos areno-argilosos (MMA/SRH 1997). No delta do Rio Caravelas predominam relevos do tipo Plano, ou ainda suave ondulado (IBGE 2004). A região é geologicamente marcada por uma extensa cobertura sedimentar, do período Quaternário, notadamente nas regiões de Caravelas e Nova Viçosa (MMA/SRH 1997). Nesta extensa planície Quaternária o rio meandra em conseqüência de sua baixa capacidade de carga, por estar próximo ao nível do mar.

A vegetação natural nos "Tabuleiros" ao longo do vale do Rio Peruípe é a Floresta Ombrófila Densa, com formações arbóreas de grande porte. Nos dias de hoje o terço superior da bacia é ocupado por pastagens, com a dominância de gramíneas. No terço médio, a vegetação secundária, como as Capoeiras, predomina constatandose a presença de mata mesófila (IBGE 2004). Na baixada litorânea, com relevo plano ou ainda suave-ondulado, persiste a floresta tropical perenifólia de restinga, estando presentes o brejo, a várzea e os campos salinos (MMA/SRH 1997). Na região da desembocadura do Rio Caravelas, em Nova Viçosa, a vegetação com influência fluviomarinha aparece em grandes extensões, nas quais sobressaem os mangues arbóreos com espécies de até 20 metros (IBGE 2004). Na região do vale do Peruípe ocorrem elevados índices pluviométricos relacionados com a predominância do clima Af, segundo a classificação Köppen, que caracteriza clima quente com temperatura superior a $18{ }^{\circ} \mathrm{C}$ no mês mais frio. Este tipo climático corresponde ao de florestas tropicais quentes e úmidas, e com temperaturas médias anuais elevadas, em torno de 21,5 a $24,5^{\circ} \mathrm{C}$ (Pinto 2004). 


\section{Bacia do Rio Peruípe}

Localizada entre os paralelos $17^{\circ} 24^{\prime}$ e $17^{\circ} 58^{\prime} \mathrm{S}$ e os meridianos $39^{\circ} 21^{\prime}$ e $40^{\circ} 09^{\prime}$ W, a bacia está limitada ao norte pela Bacia do Rio Itanhém, ao sul e oeste pela Bacia do Rio Mucuri, e a leste pelo Oceano Atlântico (Figuras 1, 2 e 3).

A bacia do Rio Peruípe ocupa uma área de $4.780 \mathrm{~km}^{2}$ (MMA/SRH 1997) e apresenta uma densa malha de drenagem em forma de leque. Possui muitos tributários, entre os quais se destacam os rios Peruípe Sul e Peruípe Norte. O Rio Peruípe Sul nasce a aproximadamente $345 \mathrm{~m}$ de altitude, no município de Ibirapuã, próximo à divisa estadual Minas Gerais - Bahia (Figura 3), com uma extensão de 63 km e possui sentido de escoamento nordeste até sua confluência com o Rio Peruípe Norte. Seu principal tributário é o Rio do Meio ou Rio do Pato, que nasce a uma altitude aproximada de 248 m, no município de Ibirapuã. O principal formador do Rio do Meio é o Córrego do Queijada. O Rio

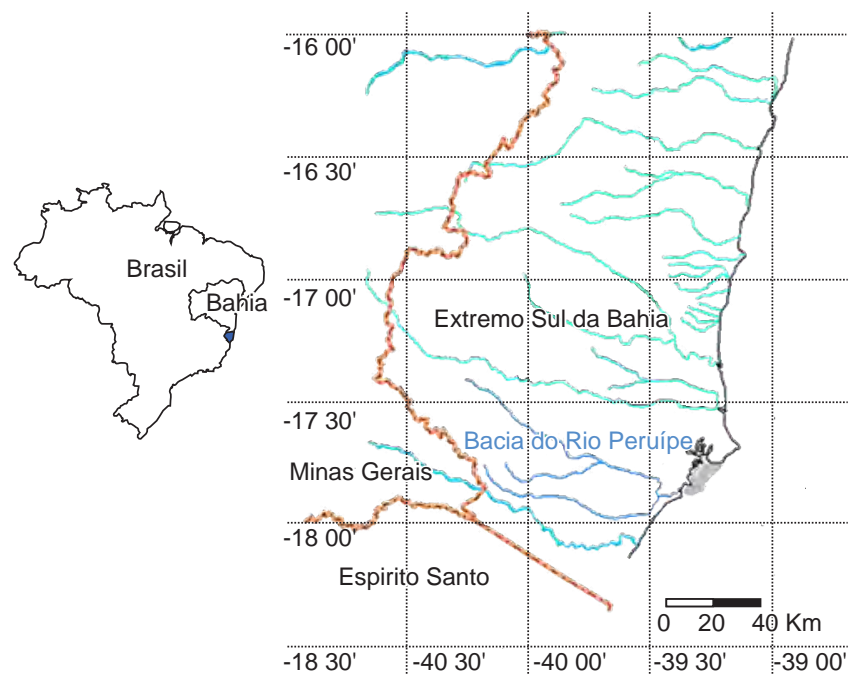

Figura 1. Localização da bacia do Rio Peruípe.

Figure 1. Location of the Rio Peruípe basin.
Peruípe Norte é formado pelas confluências do Córrego do Vinho e Córrego Barcelona. O Córrego do Vinho nasce a aproximadamente $220 \mathrm{~m}$ de altitude, próximo à fronteira dos municípios de Medeiros Neto e Caravelas, e desce suavemente até juntar-se ao curto Córrego Barcelona para formar o Rio Peruípe Norte. Este braço da bacia tem uma extensão de $45 \mathrm{~km}$ e seu sentido de escoamento é sudeste, até o ponto de confluência deste com o Rio Peruípe Sul. O Rio Peruípe recebe este nome após a confluência dos Rios Peruípe Norte e Peruípe Sul, aproximadamente $5 \mathrm{~km}$ à montante da cidade de Helvécia, e tem uma extensão de 58 km (MMA/SRH 1997). O Rio Pau Alto nasce a aproximadamente $198 \mathrm{~m}$ de altitude, próximo à fronteira entre Minas Gerais e Bahia e forma uma bacia mais ao Sul correndo no sentido Oeste-Leste, só indo encontrar o Rio Peruípe praticamente na sua Foz. Um dos formadores do Rio Pau Alto é o Córrego da Estiva.

Optou-se por dividir a bacia em trechos de acordo com os quadrantes longitudinais. O curso superior do Rio Peruípe é considerado como sendo a malha fluvial entre as longitudes $40^{\circ} 00^{\prime} \mathrm{W}$ e $40^{\circ} 30^{\prime} \mathrm{W}$; o curso médio entre as longitudes $40^{\circ} 00^{\prime} \mathrm{W}$ e $39^{\circ} 30^{\prime} \mathrm{W}$; e o baixo curso do Peruípe, localmente chamado de Rio Caravelas, está entre a longitude $39^{\circ} 30^{\prime} \mathrm{W}$ e o delta (Figura 2 ).

\section{Caracterização dos trechos amostrados na bacia}

\subsection{Terço superior}

O terço superior da bacia (Pontos 1 a 4) tem elevações que raramente ultrapassam os $300 \mathrm{~m}$. É uma região de baixa declividade, com muitas lagoas e brejos, onde longas planícies de tabuleiro dominam a paisagem. Muitos dos córregos contribuintes à bacia do Rio Peruípe têm suas nascentes em lagoas com águas paradas e vegetação submersa abundante. Outras nascentes são brejos com predomínio de vegetação emergente, como taboas. O terço superior é a porção que mais sofreu impacto por ação antrópica. Muitos dos brejos que originalmente eram nascentes dos rios foram retificados. Os relevos suaves, facilitando o acesso à ocupação humana, certamente contribuíram para o desmatamento intenso em toda a região. Nos dias de hoje predominam na paisagem as atividades agrícolas e as pastagens para gado (Tabelas 1 e 2 , Figuras 2 e 4 ).

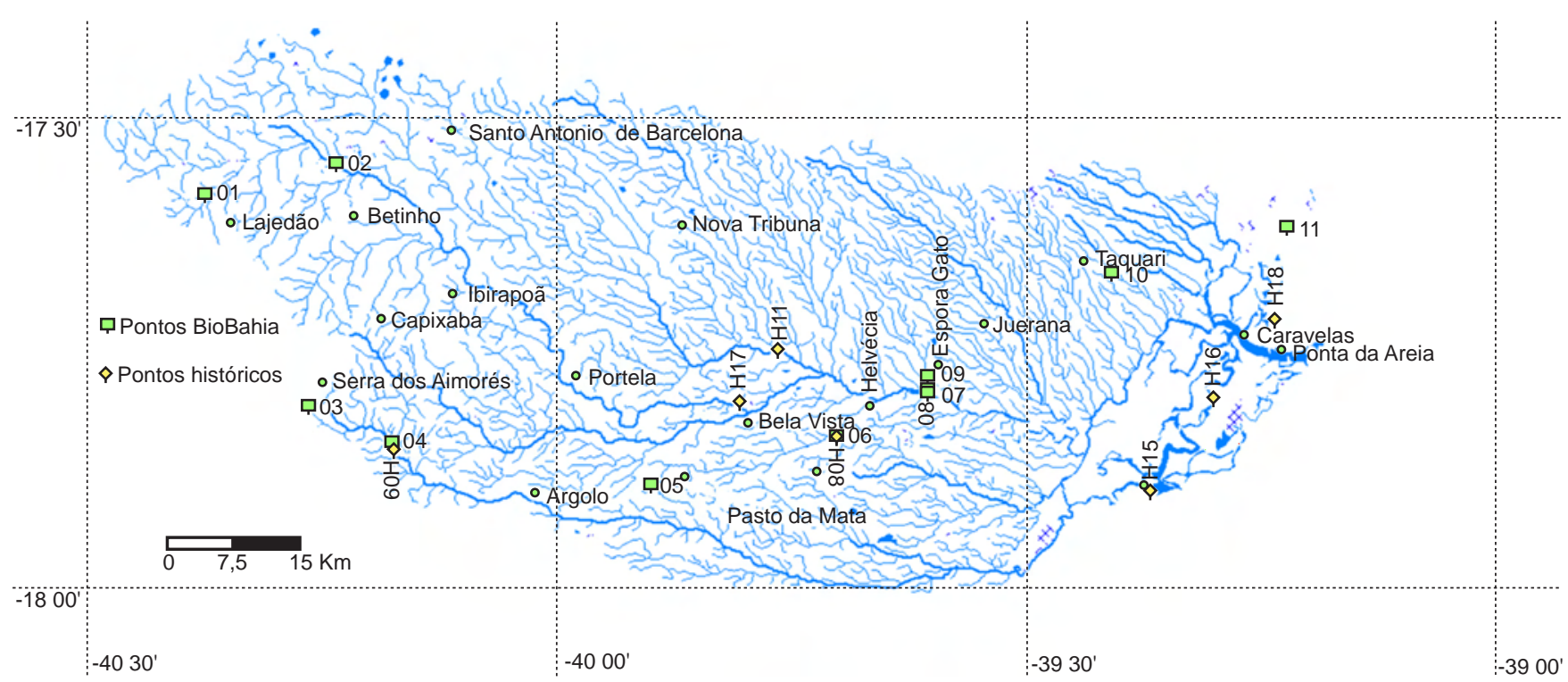

Figura 2. Mapa da bacia do Rio Peruípe indicando os onze pontos de amostragem recentes e os pontos de amostragem histórica.

Figure 2. Drainage map of Rio Peruípe with indications of the eleven collecting localities and historical samples. 


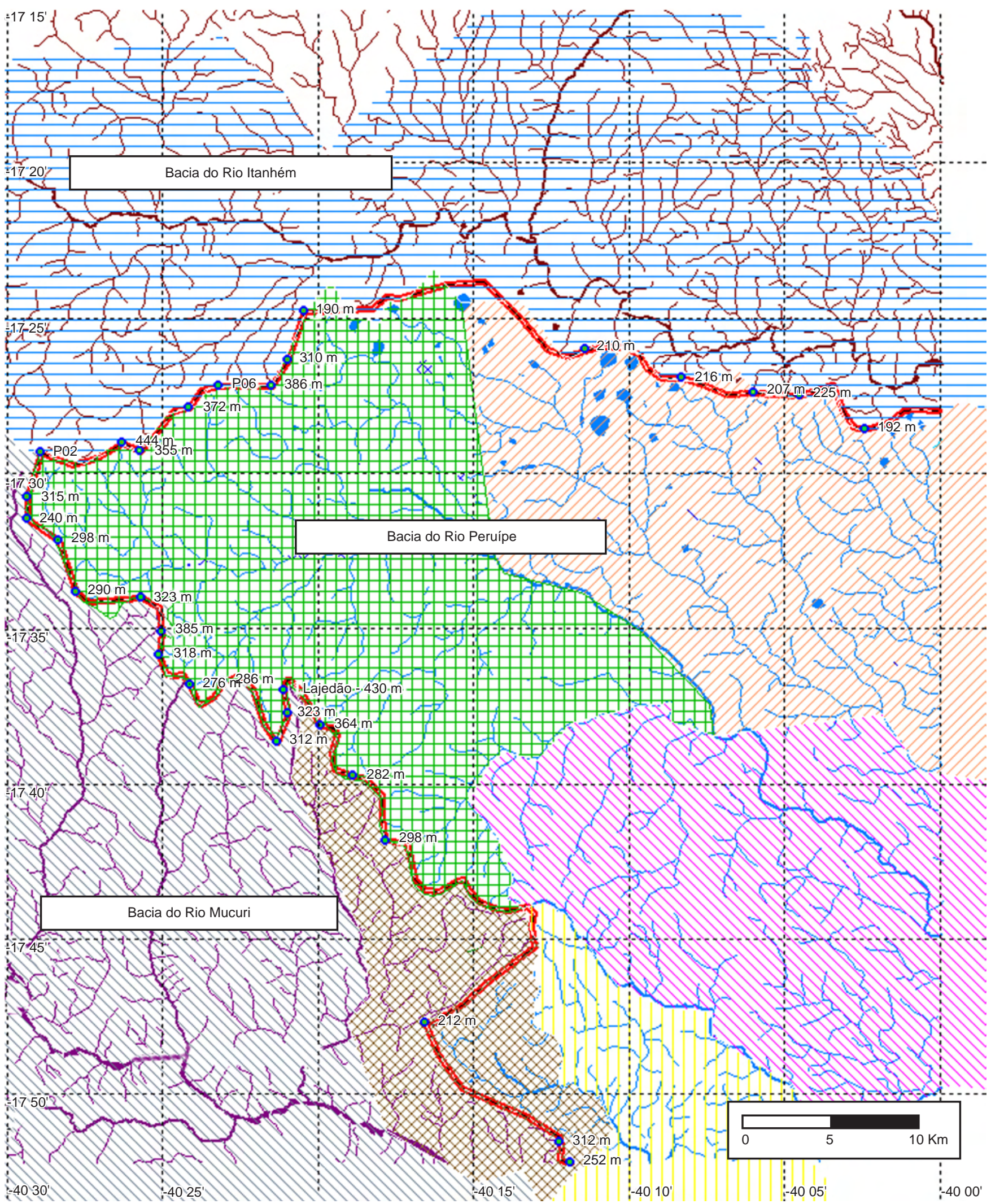

Figura 3. Mapa das nascentes do Rio Peruípe e drenagens vizinhas, na divisa estadual Bahia e Minas Gerais. Áreas hachuradas correspondem ao contorno dos municípios: Medeiros Neto (azul escuro), Lajedão (verde), Caravelas (laranja), Ibirapuã (rosa), Mucuri (amarelo), Serra dos Aimorés (marrom), Nanuque (roxo). Linha vermelha espessa indica os divisores de águas.

Figura 3. Map of headwaters of Rio Peruípe and neighbor drainages, on state boundary between Bahia and Minas Gerais. Hachured areas correspond to the contour of municipalities: Medeiros Neto (dark blue), Lajedão (green), Caravelas (orange), Ibirapuã (pink), Mucuri (yellow), Serra dos Aimorés (brown), Nanuque (purple). Thick red line indicates watershed limits. 
Tabela 1. Localização e coordenadas geográficas dos pontos amostrados na bacia do Rio Peruípe.

Table 1. Localities and geographical coordinates regarding the collecting localities sampled along the Rio Peruípe basin.

\begin{tabular}{|c|c|c|c|c|}
\hline Ponto & Localidade abreviada/município/ estado & Coordenadas & Altitude (m) & Data \\
\hline 1 & Córrego do Queijada/Lajedão/BA & $\begin{array}{l}17^{\circ} 34^{\prime} 56^{\prime \prime} \mathrm{S} \\
40^{\circ} 22^{\prime} 20^{\prime \prime} \mathrm{W}\end{array}$ & 240 & $30 / 10 / 04$ \\
\hline 2 & Rio do Meio/Lajedão/BA & $\begin{array}{l}17^{\circ} 32^{\prime} 42^{\prime \prime} \mathrm{S} \\
40^{\circ} 14^{\prime} 25^{\prime \prime} \mathrm{W}\end{array}$ & 220 & $30 / 10 / 04$ \\
\hline 3 & Córrego da Estiva/Serra dos Aimorés/MG & $\begin{array}{l}17^{\circ} 48^{\prime} 27^{\prime \prime} \mathrm{S} \\
40^{\circ} 15^{\prime} 49^{\prime \prime} \mathrm{W}\end{array}$ & 190 & $30 / 10 / 04$ \\
\hline 4 & Rio Pau Alto/Mucuri, BA, divisa com Serra dos Aimorés/MG & $\begin{array}{l}17^{\circ} 50^{\prime} 52^{\prime \prime} \mathrm{S} \\
40^{\circ} 10^{\prime} 33^{\prime \prime} \mathrm{W}\end{array}$ & 150 & $31 / 10 / 04$ \\
\hline 5 & Lagoa nascente de afluente do rio Peruípe/Nova Viçosa/BA & $\begin{array}{l}17^{\circ} 53^{\prime} 31^{\prime \prime} \mathrm{S} \\
39^{\circ} 53^{\prime} 52^{\prime \prime} \mathrm{W}\end{array}$ & 90 & $01 / 11 / 04$ \\
\hline 6 & Rio tributário do rio do Meio/Nova Viçosa/BA & $\begin{array}{l}17^{\circ} 50^{\prime} 24^{\prime \prime} \mathrm{S} \\
39^{\circ} 42^{\prime} 01^{\prime \prime} \mathrm{W}\end{array}$ & 30 & $22 / 10 / 04$ \\
\hline 7 & Rio Peruípe, na BR-418/ Nova Viçosa divisa com Caravelas/BA & $\begin{array}{l}17^{\circ} 47^{\prime} 32^{\prime \prime} \mathrm{S} \\
39^{\circ} 36^{\prime} 16^{\prime \prime} \mathrm{W}\end{array}$ & 28 & $22 / 10 / 04$ \\
\hline 8 & $\begin{array}{l}\text { Tributário do Peruípe (rio do "totó")/Nova Viçosa divisa com } \\
\text { Caravelas/BA }\end{array}$ & $\begin{array}{l}17^{\circ} 47^{\prime} 26^{\prime \prime} \mathrm{S} \\
39^{\circ} 36^{\prime} 10^{\prime \prime} \mathrm{W}\end{array}$ & 28 & $22 / 10 / 04$ \\
\hline 9 & Riacho na BR-418/Caravelas/BA & $\begin{array}{l}17^{\circ} 46^{\prime} 34^{\prime \prime} \mathrm{S} \\
39^{\circ} 36^{\prime} 09^{\prime \prime} \mathrm{W}\end{array}$ & 30 & $22 / 10 / 04$ \\
\hline 10 & Rio Taquari/Nova Viçosa/BA & $\begin{array}{l}17^{\circ} 39^{\prime} 59^{\prime \prime} \mathrm{S} \\
39^{\circ} 24^{\prime} 26^{\prime \prime} \mathrm{W}\end{array}$ & 25 & $22 / 10 / 04$ \\
\hline 11 & Alagado marginal/Alcobaça/BA & $\begin{array}{l}17^{\circ} 37^{\prime} 02^{\prime \prime} \mathrm{S} \\
39^{\circ} 13^{\prime} 16^{\prime \prime} \mathrm{W}\end{array}$ & 05 & $22 / 10 / 04$ \\
\hline
\end{tabular}

Tabela 2. Informações ambientais nos pontos amostrados na bacia do Rio Peruípe.

Table 2. Environmental information regarding the collecting localities sampled along the Rio Peruípe basin.

\begin{tabular}{|c|c|c|c|c|c|c|}
\hline Ponto & Prof. amostra & Água & Substrato & Vegetação marginal & Vegetação aquática & $\begin{array}{l}\text { Vegetação de } \\
\text { entorno }\end{array}$ \\
\hline 1 & $0,5 \mathrm{~m}$ & Marrom/turva & lodo & Poucas gramíneas & Poucas taboas & Pastagem \\
\hline 2 & $1,0-1,5 \mathrm{~m}$ & Marrom/turva & $\begin{array}{l}\text { Rocha ou } \\
\text { argila }\end{array}$ & Moderadas gramíneas & $\begin{array}{l}\text { Moderadas } \\
\text { macrófitas } \\
\text { e taboas }\end{array}$ & Pastagem \\
\hline 3 & $0,5 \mathrm{~m}$ & Cor de chá/transparente & areia & Poucas gramíneas & Ausente & $\begin{array}{l}\text { Capoeira } \\
\text { agricultura }\end{array}$ \\
\hline 4 & $1,5 \mathrm{~m}$ & Marrom/turva & lodo & Moderadas gramíneas & $\begin{array}{l}\text { Moderadas macrófitas } \\
\text { e taboas }\end{array}$ & $\begin{array}{l}\text { Capoeira } \\
\text { agricultura }\end{array}$ \\
\hline 5 & $1,0 \mathrm{~m}$ & Clara/transparente & lodo & $\begin{array}{l}\text { Abundantes plantas } \\
\text { emergentes e gramíneas }\end{array}$ & $\begin{array}{l}\text { Abundantes } \\
\text { macrófitas e taboas }\end{array}$ & $\begin{array}{l}\text { Capoeira ou mata } \\
\text { secundária }\end{array}$ \\
\hline 6 & $1,0 \mathrm{~m}$ & Marrom/turva & $\begin{array}{l}\text { Areia, } \\
\text { lodo e argila }\end{array}$ & $\begin{array}{l}\text { Remanescentes de } \\
\text { mata ciliar e poucas } \\
\text { gramíneas }\end{array}$ & $\begin{array}{l}\text { Abundante vegetação } \\
\text { submersa }\end{array}$ & Eucaliptal \\
\hline 7 & $1,5 \mathrm{~m}$ & Marrom/turva & $\begin{array}{l}\text { Areia e } \\
\text { cascalho }\end{array}$ & $\begin{array}{l}\text { Remanescentes de mata } \\
\text { ciliar }\end{array}$ & $\begin{array}{l}\text { Pouca vegetação } \\
\text { submersa }\end{array}$ & Eucaliptal \\
\hline 8 & $1,5 \mathrm{~m}$ & Marrom/turva & Areia & $\begin{array}{l}\text { Remanescentes de } \\
\text { mata ciliar e moderadas } \\
\text { gramíneas }\end{array}$ & $\begin{array}{l}\text { Pouca vegetação } \\
\text { submersa }\end{array}$ & Eucaliptal \\
\hline 9 & $1,0 \mathrm{~m}$ & $\begin{array}{l}\text { Amarela/transparente a } \\
\text { levemente turva }\end{array}$ & $\begin{array}{l}\text { Cascalho e } \\
\text { pedras }\end{array}$ & $\begin{array}{l}\text { Remanescentes de } \\
\text { mata ciliar e poucas } \\
\text { gramíneas }\end{array}$ & $\begin{array}{l}\text { moderada vegetação } \\
\text { submersa }\end{array}$ & Eucaliptal \\
\hline 10 & $1,0 \mathrm{~m}$ & Cor de chá/transparente & Areia & $\begin{array}{l}\text { Remanescentes de } \\
\text { mata ciliar e moderadas } \\
\text { gramíneas }\end{array}$ & $\begin{array}{l}\text { moderada vegetação } \\
\text { submersa }\end{array}$ & mata secundária \\
\hline 11 & $0,3-0,5 \mathrm{~m}$ & $\begin{array}{l}\text { Amarelada/ } \\
\text { levemente turva }\end{array}$ & Areia e lodo & $\begin{array}{l}\text { Moderadas plantas } \\
\text { emergentes e gramíneas }\end{array}$ & $\begin{array}{l}\text { moderada vegetação } \\
\text { submersa }\end{array}$ & Restinga \\
\hline
\end{tabular}




\subsection{Terço médio}

No terço médio da bacia (Pontos 5 a 9) os gradientes de altitude vão até $150 \mathrm{~m}$. A declividade diminui suavemente nos tabuleiros, e

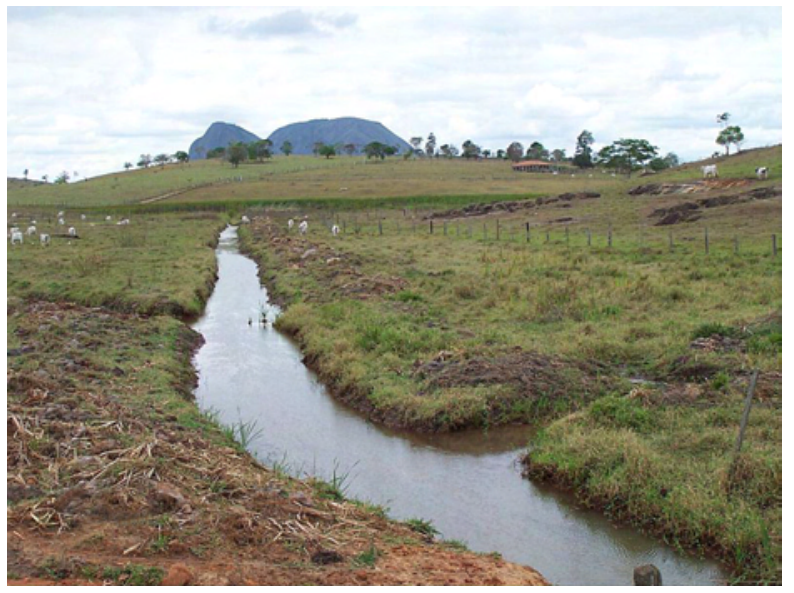

(P1)

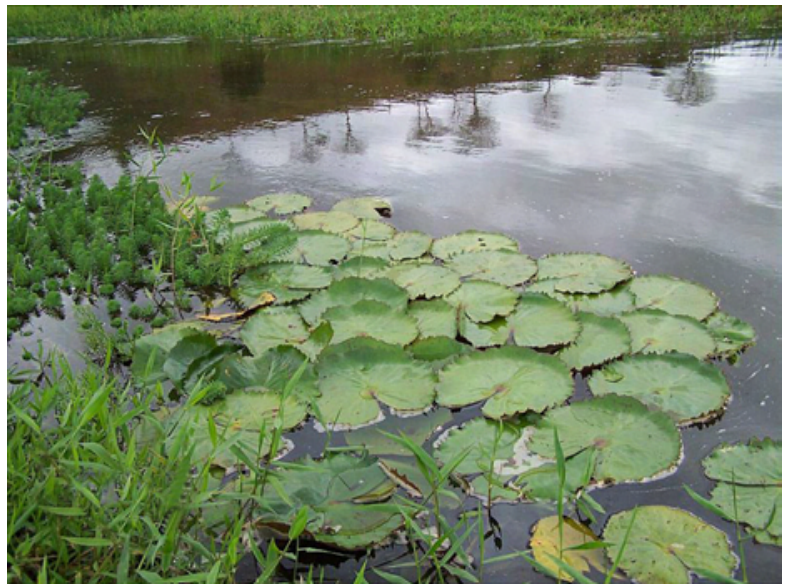

(P2b)

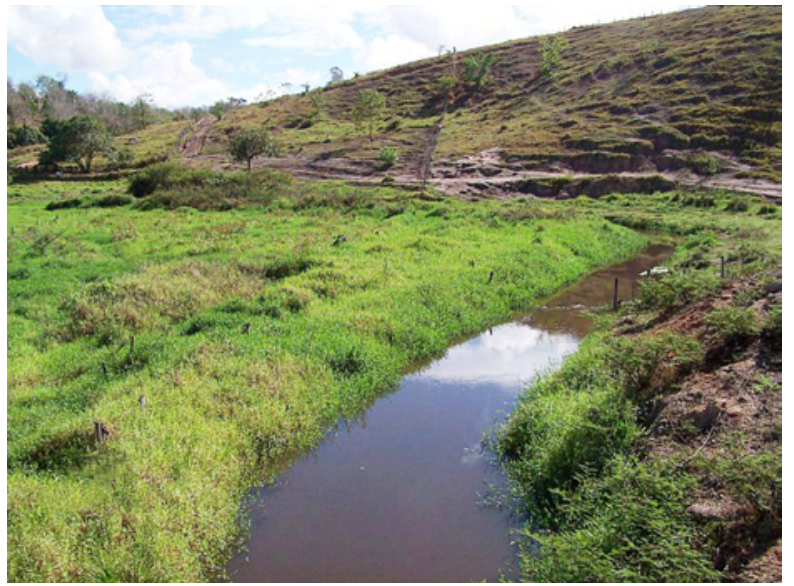

(P4) a cada dez minutos de longitude decrescente verificamos um declive variando aproximadamente entre 10 e 40 metros. O terço médio da bacia é contornado por extensas plantações de Eucaliptus sp. para abastecer a indústria de papel e celulose. Ainda há vestígios de floresta

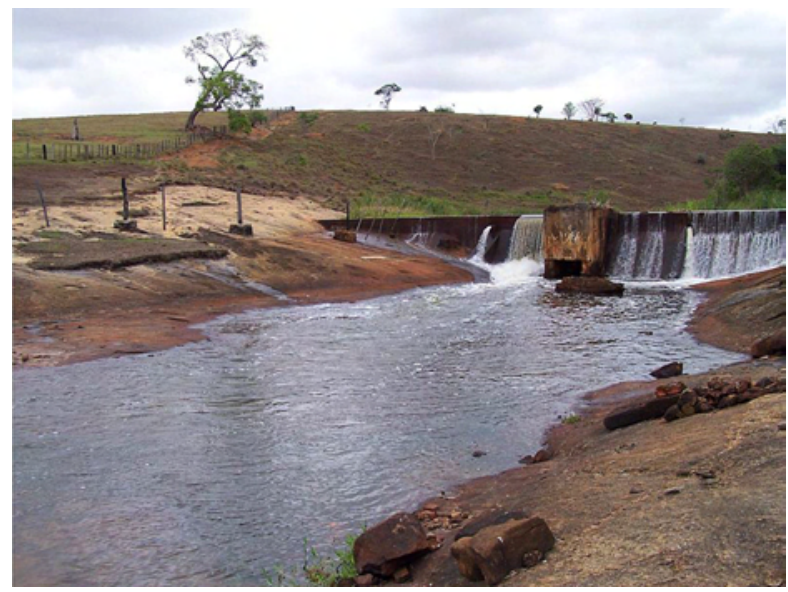

(P2a)

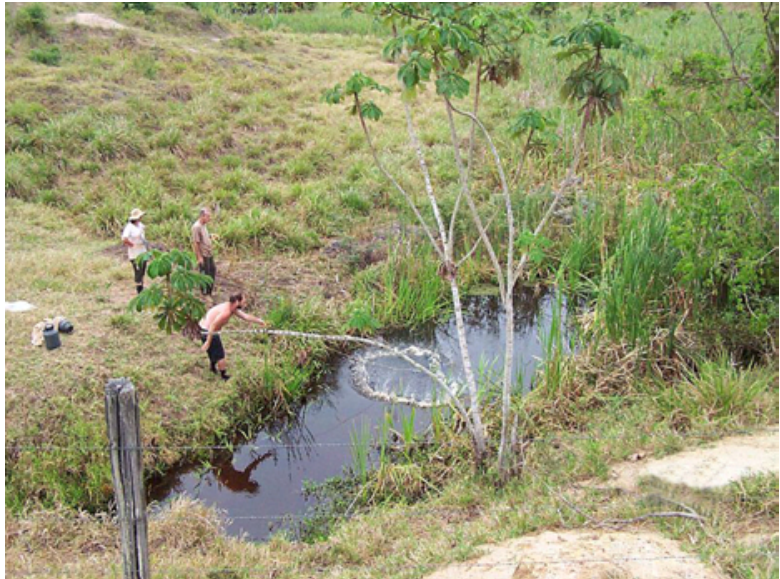

(P3)

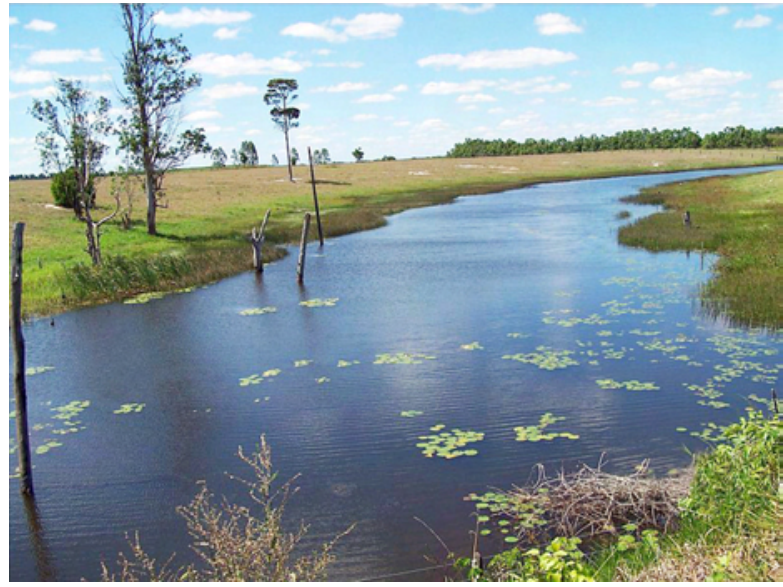

(P5)

Figura 4. Pontos de amostragem (P) ao longo da bacia do Rio Peruípe. Terço Superior: (P1) Córrego Queijada; (P2a) Rio do Meio ou Rio do Pato, aspecto geral do Rio onde está represado; (P2b) Rio do Meio ou Rio do Pato, vegetação à jusante da represa; (P3) Córrego da Estiva; (P4) Rio Pau Alto. Terço Médio: (P5) Lagoa nascente de afluente do Rio Peruípe.

Figure 4. Collecting localities (P) along the Rio Peruípe basin. Upper portion: (P1) Córrego Queijada; (P2a) Rio do Meio or Rio do Pato, general aspect of the place where the river is dammed up; (P2b) Rio do Meio or Rio do Pato, vegetation below the dam; (P3) Córrego da Estiva; (P4) Rio Pau Alto. Middle portion: (P5) Lake nascent of a tributary of the Rio Peruípe. 
e persistem remanescentes de mata ciliar ao longo das margens dos rios (Tabelas 1 e 2, Figuras 2, 4 e 5).

\subsection{Terço inferior}

No terço inferior da bacia (Pontos 10 e 11) os gradientes de altitude variam entre $30 \mathrm{~m}$ até o nível do mar. Forma-se uma extensa

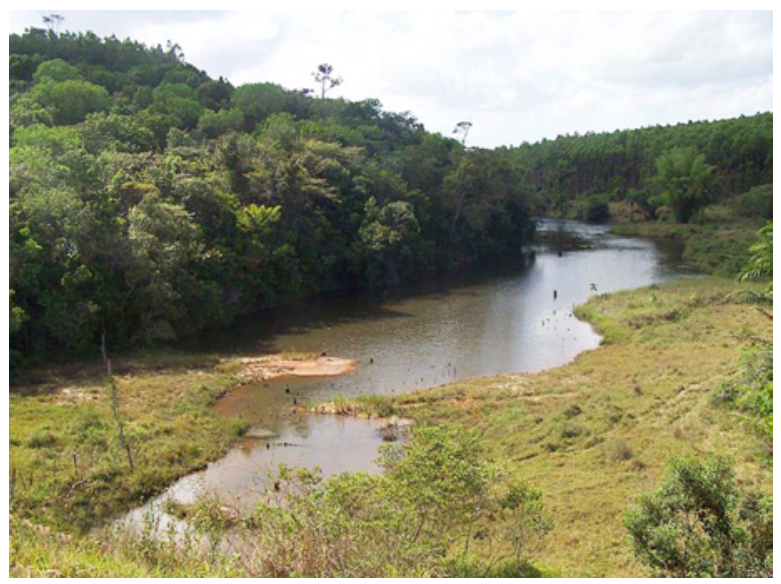

(P6)

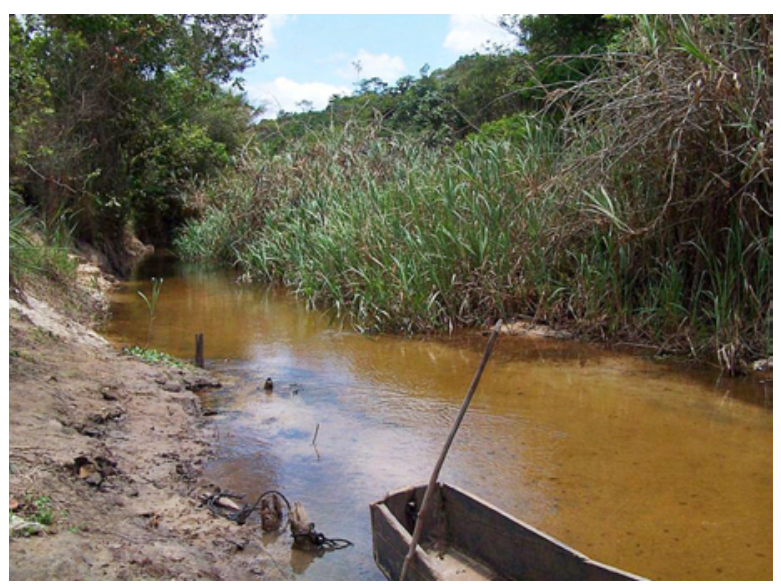

(P8)

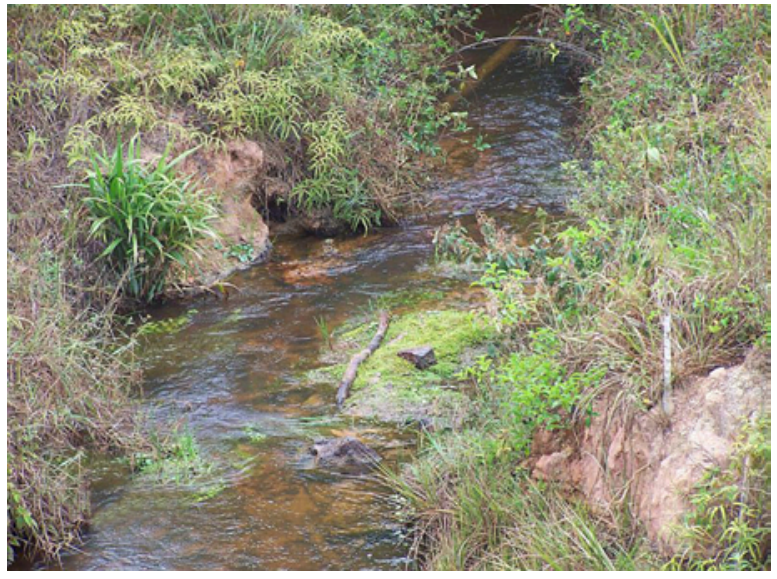

(P10) baixada litorânea com relevo quase plano. São encontrados amplos alagados de águas rasas às margens dos rios que formam o delta do Rio Caravelas. As plantações de Eucalyptus sp. diminuem nos trechos mais próximos ao litoral, restando as matas secundárias, as restingas e os manguezais na paisagem do entorno da bacia (Tabelas 1 e 2, Figuras 2 e 5).

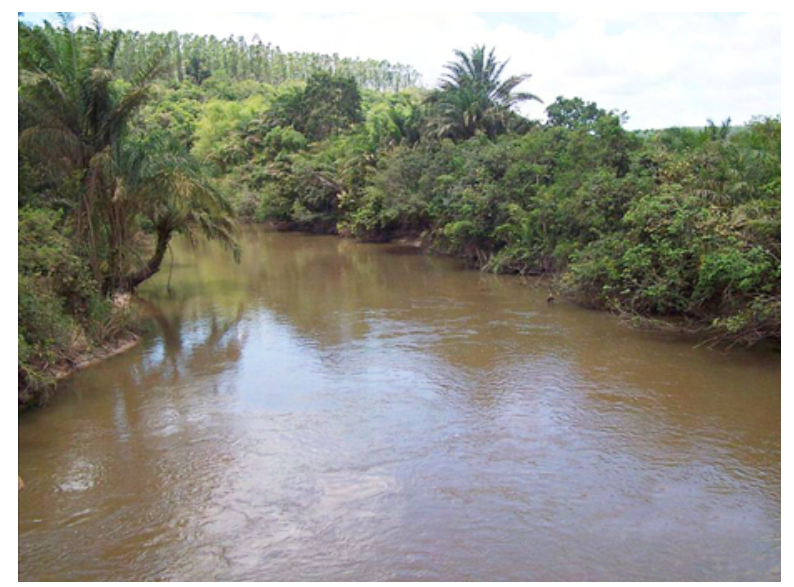

(P7)

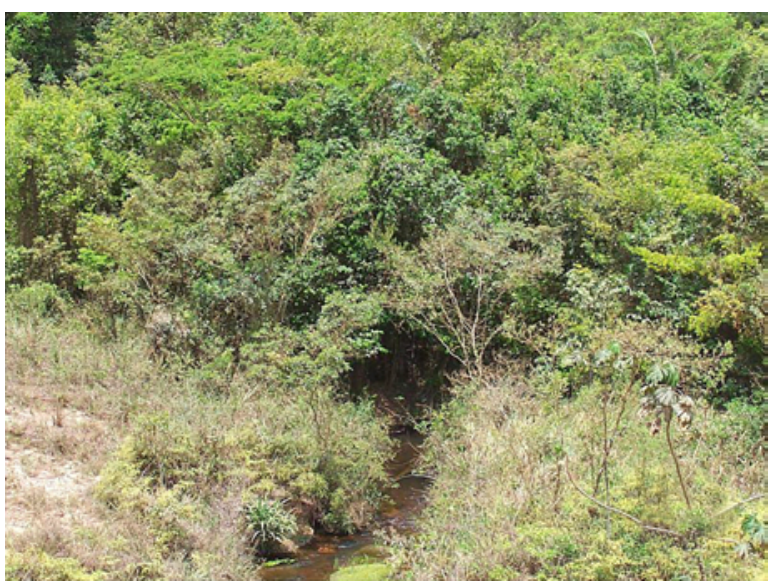

(P9)

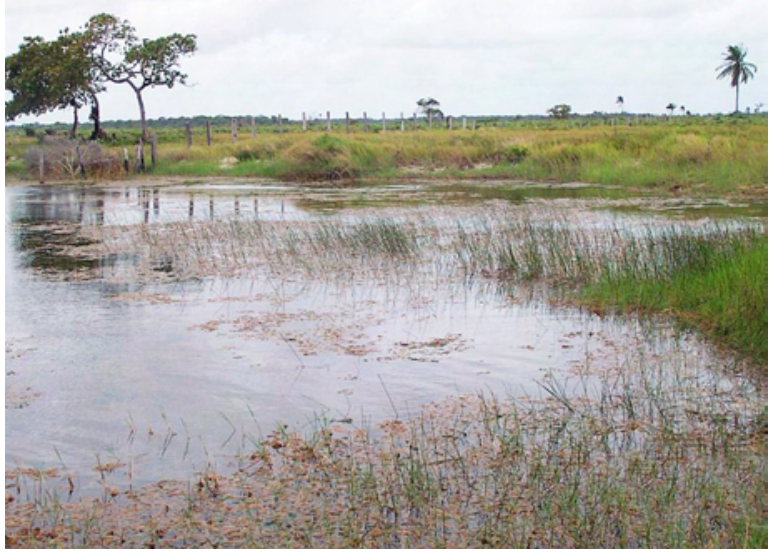

(P11)

Figura 5. Pontos de amostragem (P) ao longo da bacia do Rio Peruípe. Terço Médio: (P6) Córrego afluente do Rio Peruípe; (P7) Rio Peruípe na estrada BR-418; (P8) Rio do Totó; (P9) Riacho na estrada BR-418. Terço inferior: (P10) Rio Taquari; (P11) Alagado marginal na estrada BA-001.

Figure 5. Collecting localities (P) along the Rio Peruípe basin. Middle portion: (P6) A stream tributary of Rio Peruípe; (P7) Rio Peruípe on road BR-418; (P8) Rio Totó; (P9) Stream on road BR-418. Lower portion: (P10) Rio Taquari; (P11) Coastal lagoon close to road BA-001. 


\section{Amostragem}

Devido às condições históricas de sub-amostragem da área de estudo, principalmente no que se refere às cabeceiras dos rios e riachos a maior parte das atividades de campo no âmbito do projeto BioBahia foram dirigidas para os trechos superior e médio dos rios. As atividades de campo foram realizadas durante o dia, pela manhã até o crepúsculo. Os pontos de amostragem foram previamente planejados, levando-se em conta o acesso, inclusive as travessias por vias menores não pavimentadas.

Cada um dos pontos de amostragem foi localizado por GPS (Global Positioning System), anotado quanto à altitude e fotografado. As seguintes condições ambientais foram verificadas: profundidade de amostragem, cor e transparência da água, tipo de substrato do leito, tipo de vegetação marginal, aquática e de entorno. Foram, ainda, realizadas anotações sobre horário e artefatos de pesca empregados. As amostragens foram realizadas com o uso de puçás, picarés, "covos", redes e tarrafas. Casos em que os métodos convencionais revelaram-se pouco eficientes foi empregado o mergulho livre para localização e captura de exemplares. Os exemplares coletados foram fotografados vivos, em aquário de campo, fixados em formalina a $10 \%$ e transportados para o laboratório, onde foram triados, transferidos para conservação em álcool a 70\%, identificados e catalogados. A relação do material coletado e identificado encontra-se disponibilizada em Sarmento-Soares \&
Martins-Pinheiro, 2007a. Em uma parcela dos indivíduos capturados foram tomadas medidas morfométricas, efetuadas dissecções para averiguar o estágio de maturidade sexual e ainda examinar o conteúdo estomacal. Os exemplares catalogados foram incorporados ao acervo ictiológico do Museu Nacional, Universidade Federal do Rio de Janeiro - MNRJ. A licença de coleta para a expedição foi solicitada junto ao Instituto Brasileiro do Meio Ambiente e dos Recursos Naturais Renováveis - IBAMA (autorização número 10950-1).

\section{Taxonomia}

A classificação taxonômica dos exemplares seguiu Buckup et al. (2007) para peixes de água doce e Carvalho Filho (1999) e Menezes et al. (2003) para peixes marinhos. Exemplares que apresentaram dúvidas sobre sua identificação foram diafanizados, para avaliação morfológica detalhada. As espécies capturadas estão listadas por ponto (Tabela 3) e por grupo taxonômico (Tabela 4). Além do material capturado, foi consultado o acervo das coleções ictiológicas do Museu Nacional - MNRJ, como uma complementação do conhecimento da ictiofauna da região (Sarmento-Soares \& Martins-Pinheiro. 2007b). Informações históricas acerca da ictiofauna na região de estudo, foram obtidas a partir de consulta ao banco de dados do projeto NEODAT (The Inter-Institutional Database of Fish Biodiversity in the Neotropics - NEODAT Project/ NSF) e a partir de relatório

Tabela 3. Relação das espécies coletadas (assinaladas por um X) na Bacia do Rio Peruípe por ponto amostrado (P).

Table 3. List of species captured (signed by an X) in the Rio Peruípe basin by collecting locality (P).

\begin{tabular}{|c|c|c|c|c|c|c|c|c|c|c|c|}
\hline \multirow[t]{2}{*}{ Espécie/Trecho } & \multicolumn{4}{|c|}{ Alto } & \multicolumn{5}{|c|}{ Médio } & \multicolumn{2}{|c|}{ Baixo } \\
\hline & P1 & $\mathbf{P 2}$ & P3 & P4 & P5 & P6 & P7 & P8 & P9 & P10 & P11 \\
\hline Characidium sp. & & $\mathrm{X}$ & & & & $\mathrm{x}$ & & & & & \\
\hline Astyanax cf. lacustris & $\mathrm{x}$ & & $\mathrm{x}$ & $\mathrm{x}$ & & & & $\mathrm{x}$ & & & $\mathrm{x}$ \\
\hline Astyanax cf. rivularis & $\mathrm{x}$ & $\mathrm{X}$ & $\mathrm{X}$ & & & $\mathrm{X}$ & & $\mathrm{X}$ & & $\mathrm{X}$ & \\
\hline Hyphessobrycon bifasciatus & & & $\mathrm{X}$ & & $\mathrm{X}$ & $\mathrm{X}$ & & & & $\mathrm{X}$ & $\mathrm{X}$ \\
\hline Oligosarcus acutirostris & & $\mathrm{x}$ & $\mathrm{x}$ & $\mathrm{x}$ & & & & & & & \\
\hline Tetragonopterus cf. chalceus & & & & $\mathrm{x}$ & $\mathrm{x}$ & & & $\mathrm{X}$ & & & \\
\hline Mimagoniates microlepis & & & & & & & & & & $\mathrm{X}$ & \\
\hline Hoplerythrinus unitaeniatus & & & & & $\mathrm{x}$ & & & & & & \\
\hline Hoplias malabaricus & $\mathrm{x}$ & $\mathrm{x}$ & $\mathrm{x}$ & $\mathrm{x}$ & & $\mathrm{x}$ & & $\mathrm{x}$ & & & $\mathrm{x}$ \\
\hline Trichomycterus pradensis & & & & & & & & & $\mathrm{x}$ & & \\
\hline Aspidoras virgulatus & & & & & & & & & & $\mathrm{X}$ & \\
\hline Scleromystax prionotos & & & $\mathrm{X}$ & $\mathrm{X}$ & & $\mathrm{X}$ & & $\mathrm{X}$ & & & \\
\hline Hypostomus sp. & & $\mathrm{X}$ & & & & & & & & & \\
\hline Otothyris travassosi & & $\mathrm{X}$ & & $\mathrm{X}$ & & $\mathrm{X}$ & & & & $\mathrm{X}$ & \\
\hline Imparfinis cf. minutus & & & & & & $\mathrm{x}$ & & & $\mathrm{x}$ & & \\
\hline Pimelodella cf. vittata & & & & $\mathrm{x}$ & & $\mathrm{X}$ & & $\mathrm{x}$ & & & \\
\hline Rhamdia sp. & & & & & & $\mathrm{X}$ & & $\mathrm{X}$ & & & \\
\hline Microglanis pataxo & & & & $\mathrm{x}$ & & $\mathrm{x}$ & & & $\mathrm{x}$ & & \\
\hline Parauchenipterus striatulus & & & & & & $\mathrm{X}$ & $\mathrm{X}$ & $\mathrm{X}$ & & & \\
\hline Phalloceros sp. & & & & & & & & & & $\mathrm{x}$ & \\
\hline Poecilia vivipara & $\mathrm{X}$ & $\mathrm{X}$ & & $\mathrm{X}$ & $\mathrm{X}$ & $\mathrm{X}$ & & $\mathrm{X}$ & & & \\
\hline Synbranchus marmoratus & & & & & & & & & & $\mathrm{X}$ & \\
\hline Australoheros sp. & & & & $\mathrm{x}$ & & $\mathrm{x}$ & & & & & \\
\hline Crenicichla lacustris & & & & & & & & & $\mathrm{x}$ & & \\
\hline Geophagus brasiliensis & $\mathrm{X}$ & $\mathrm{x}$ & $\mathrm{x}$ & $\mathrm{x}$ & $\mathrm{X}$ & $\mathrm{x}$ & & & $\mathrm{x}$ & $\mathrm{x}$ & $\mathrm{x}$ \\
\hline Trinectes paulistanus & & & & & & & $\mathrm{X}$ & $\mathrm{x}$ & & & \\
\hline Total & 5 & 8 & 7 & 11 & 5 & 14 & 2 & 10 & 5 & 8 & 4 \\
\hline
\end{tabular}


Tabela 4. Lista taxonômica das espécies de Peixes Registradas para a Bacia do rio Peruípe. Espécies indicadas por asterisco.

Table 4. Taxonomic list of fish species recorded for the rio Peruípe. Species indicated by an asterisk.

\section{ACTINOPTERYGII \\ CHARACIFORMES}

Curimatidae

Cyphocharax gilbert (Quoy \& Gaimard, 1824) (*)

Anostomidae

Leporinus copelandii Steindachner, 1875 (*)

Crenuchidae

Characidiinae

Characidium sp.

Characidae

Incertae sedis

Astyanax cf. lacustris (Lütken, 1875)

Astyanax cf. rivularis (Lütken, 1875)

Hyphessobrycon bifasciatus Ellis, 1911

Moenkhausia doceana (Steindachner, 1877) (*)

Oligosarcus acutirostris Menezes, 1987

Tetragonopterinae

Tetragonopterus cf. chalceus Spix \& Agassiz, 1829

Glandulocaudinae

Mimagoniates microlepis (Steindachner, 1876)

Erythrinidae

Hoplerythrinus unitaeniatus (Agassiz, 1829)

Hoplias malabaricus (Bloch, 1794)

\section{SILURIFORMES}

Trichomycteridae

Trichomycterus pradensis Sarmento-Soares et al. 2005

Callichthyidae

Aspidoradini

Aspidoras virgulatus Nijssen \& Isbrüecker, 1980

Scleromystax prionotos (Nijssen \& Isbrüecker, 1980)

Loricariidae

Hypoptopomatinae

Otothyris travassosi Garavello, Britski \& Schaeffer, 1998

Hypostominae

Hypostomus sp.

Heptapteridae

* referem-se a registros históricos

* correspond to historical records.

técnico disponível (MMA/SRH 1999). Os pontos de amostragem e as espécies listadas nestas informações históricas estão relacionados nas Tabelas 5 e 6.

\section{Análise das amostras}

O método de constância de ocorrência (Dajoz 1973) foi empregado para averiguar a presença das espécies ao longo da bacia. O cálculo da constância foi baseado no percentual do número de coletas com aparecimento da espécie, dividido pelo número total de coletas. Foram consideradas como constantes as espécies com mais de 50\% de constância de ocorrência; como acessórias as espécies com constância entre 25 e $50 \%$ e como ocasionais aquelas com menos de $25 \%$ de constância. A classificação das espécies por ponto segundo constância de ocorrência consta da tabela 7. Para a estimativa da riqueza, diversidade, equitabilidade e dominância de espécies foi utilizado o programa PAST (Versão 1.72)
Imparfinis cf. minutus (Lütken, 1874)

Pimellodella cf. vittata (Lütken, 1874)

Rhamdia sp.

Pseudopimelodidae

Microglanis pataxo Sarmento-Soares et al., 2006

Auchenipteridae

Pseudauchenipterus affinis (Steindachner, 1877) (*)

Parauchenipterus striatulus (Steindachner, 1877)

Gymnotiformes

Gymnotidae

Gymnotus carapo Linnaeus, 1758(*)

CYPRINODONTIFORMES

Poeciliidae

Phalloceros sp.

Poecilia vivipara Bloch \& Schneider, 1801

GASTEROSTEIFORMES

Syngnathidae

Microphis brachyurus (Bleeker, 1853) (*)

SYNBRANCHIFORMES

Synbranchidae

Synbranchus marmoratus Bloch, 1795

\section{PERCIFORMES}

Centropomidae

Centropomus paralellus Poey, $1860(*)$

Cichlidae

Australoheros sp. (Jenyns, 1842)

Crenicichla lacustris (Castelnau, 1855)

Geophagus brasiliensis (Quoy \& Gaimard, 1824)

Gobiidae

Awaous tajasica Lichtenstein, 1822 (*)

PLEURONECTIFORMES

Paralichthydae

Paralichthys brasiliensis (Ranzani, 1840) (*)

Achiridae

Achirus lineatus (Linnaeus, 1758) (*)

Trinectes paulistanus (Miranda-Ribeiro, 1915)

(Hammer et al. 2001). Foram utilizados os seguintes estimadores de riqueza: Chao 2, Jackknife 1, Jackknife 2 e Bootstrap. Os estimadores empregados são algoritmos não paramétricos que estimam o número de espécies ainda por serem coletadas, baseados numa quantificação de raridade. Os estimadores Chao 2, Jackknife 1, Jackknife 2 e Bootstrap são baseados em incidência e utilizam o número de "Uniques" e "Duplicates", que são o número de espécies encontradas em somente uma ou duas amostras, respectivamente, para as estimativas de riqueza (Colwell \& Coddington 1994). As estimativas de riqueza de espécies estão indicadas na Tabela 8 As curvas de rarefação espécies-área foram geradas para verificar a suficiência da amostragem, com o método Mao Tau (Colwell et al., 2004). A equitabilidade foi determinada conforme Pielou (1969). A diversidade e dominância foram verificadas conforme indicado em índices de dominância, diversidade e equitabilidade estão indicados na tabela 9. Vieira \& Shibata (2007). 

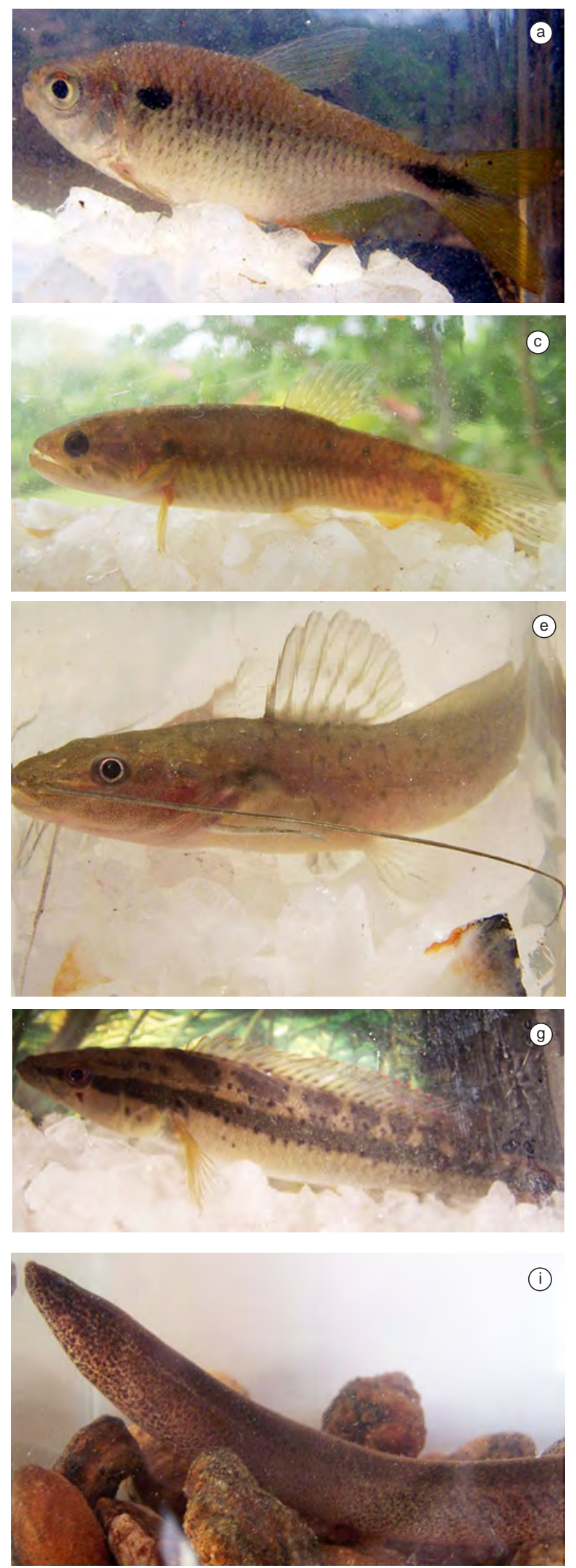
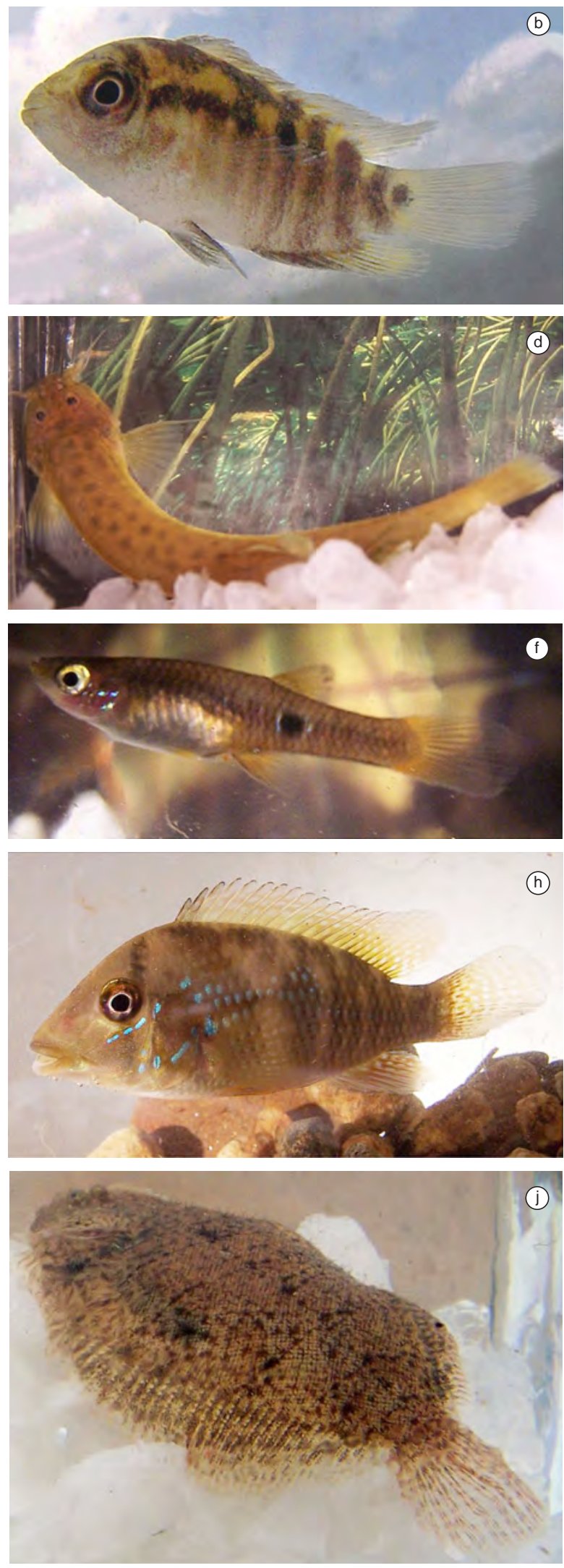

Figura 6. Algumas espécies de peixes na bacia do Rio Peruípe: a) Astyanax cf. lacustris; b) Australoheros sp.; c) Hoplerytrynus unitaeniatus; d) Trichomycterus pradensis; e) Rhamdia sp.; f) Phalloceros sp.; g) Crenicichla lacustris; h) Geophagus brasiliensis; i) Synbranchus marmoratus; e j) Trinectes paulistanus.

Figure 6. Some representative fish species along the Rio Peruípe river basin: a) Astyanax cf. lacustris; b) Australoheros sp.; c) Hoplerytrynus unitaeniatus;

d) Trichomycterus pradensis; e) Rhamdia sp.; f) Phalloceros sp.; g) Crenicichla lacustris; h) Geophagus brasiliensis; i) Synbranchus marmoratus; and j) Trinectes paulistanus. 


\section{Resultados}

\section{A ictiofauna do Rio Peruípe}

Foi coletado em toda a bacia do Rio Peruípe um total de 26 espécies, pertencentes a 12 famílias em 6 ordens (Tabela 3, Figura 6). As espécies de peixes encontradas ao longo da bacia foram representadas pelas ordens Siluriformes (10 espécies, 38,5\%) seguida por Characiformes (9 espécies, 34.6\%), Perciformes (3 espécies, 11,5\%), Cyprinodontiformes (2 espécies, 7,7\%), e ainda Synbranchiformes e Pleuronectiformes (1 espécie cada, 3,8\%) (Tabela 3).

Das 26 espécies coletadas Microglanis pataxo SarmentoSoares et al. 2006 e Trichomycterus pradensis Sarmento-Soares et al. 2005 foram recentemente descritas e ainda outras duas foram reconhecidas como novas: Australoheros sp. e Phalloceros sp. A identificação de Australoheros sp. seguiu a recomendação de Rican \& Kullander (2006), que reconheceram a existência de várias populações no Brasil, porém a identificação taxonômica a nível específico exige a revisão do gênero. Situação semelhante se aplica a Phalloceros sp., reconhecida como nova e em processo de descrição no âmbito de revisão genérica (P. Lucinda, com. pess.). Muitos grupos supra-específicos carecem de identificação disponível em literatura para a região. As espécies destes grupos foram identificadas com "status" taxonômico ainda indefinido, como foi o caso de Characidium sp., Rhamdia sp. e Hypostomus sp. Tetragonopterus cf. chalceus foi identificado em associação com a espécie presente em rios costeiros do nordeste e pode ser nova. As espécies de peixes registradas para a bacia do Rio Peruípe são todas nativas da região. Das espécies com registro histórico para a bacia, 75 espécies invasoras marinhas foram encontradas nas proximidades do delta do Rio Caravelas (Tabela 5). As seguintes espécies com registro histórico nas partes média e alta não foram confirmadas em nossas coletas: Gymnotus carapo, Parotocinclus sp., Moenkhausia doceana, Centropomus sp., Cyphocharax gilbert e Leporinus sp. Com exceção de Moenkhausia doceana, as demais foram encontradas em bacias vizinhas. O pequeno esforço de captura na calha central dos grandes rios pode ter contribuído para a não captura de Centropomus sp., Cyphocharax gilbert e Leporinus sp. Por outro lado a coleta em tributários menores foi compensada pela localização das seguintes espécies ainda não assinaladas para a bacia: Crenicichla lacustris, Hoplerythrinus unitaeniatus, Hypostomus sp., Imparfinis cf. minutus, Mimagoniates microlepis, Phalloceros sp., Rhamdia sp., Synbranchus marmoratus, Tetragonopterus cf. chalceus e Trichomycterus pradensis. No Rio Peruípe as espécies capturadas não excederam $150 \mathrm{~mm} \mathrm{CP}$, e as menores espécies apresentaram tamanho adulto inferior a $50 \mathrm{~mm} \mathrm{CP}$.

Quatro espécies foram consideradas constantes, encontradas em mais da metade dos pontos amostrados e nove foram consideradas acessórias. As 13 restantes foram reconhecidas como ocasionais (Tabela 7). As estimativas de riqueza de espécies variaram $18,3 \%$ entre a estimativa Bootstrap e a Jackknife 2. A estimativa Bootstrap foi a mais baixa, com aproximadamente 29 espécies e a Jackknife 2 foi a maior, com aproximadamente 36 espécies. As estimativas dos outros dois métodos foram semelhantes entre si e apresentaram valores intermediários aos de Bootstrap e Jackknife 2 (Tabela 6). A curva de rarefação espécies-área pelo método Mao Tau (Figura 7) indica uma tendência à estabilização, considerando que com metade dos pontos de coleta, cerca de $77 \%$ das espécies foram amostradas. As espécies de pequeno porte, menores que $50 \mathrm{~mm} \mathrm{CP}$, apareceram ao longo de toda a bacia. Foram representadas principalmente por pequenos Siluriformes, como Aspidoras virgulatus, Otothyris travassosi, Microglanis pataxo e ainda pelos poecilídeos Poecilia vivipara e Phalloceros sp. Nas cabeceiras do

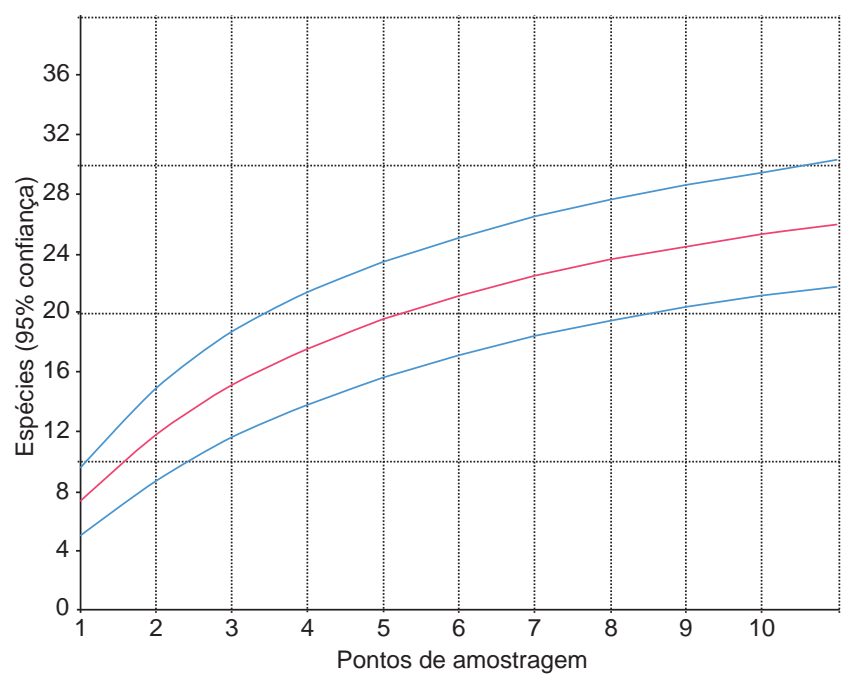

Figura 7. Curva de rarefação espécies-área pelo método Mao Tau.

Figure 7. Species-area rarefation curve according to Mao Tau method.

Rio Peruípe predominaram as espécies de menor porte, com indivíduos medindo no máximo $70 \mathrm{~mm} \mathrm{CP}$, sendo que Hypostomus sp. e Oligosarcus acutirostris, foram encontradas unicamente nesta porção do rio. Nos trechos alto e médio houve baixa dominância das espécies $\mathrm{D}<0,2$ (Tabela 7). O maior índice de dominância (D>3) observado no trecho baixo deveu-se à elevada abundância de Astyanax cf. lacustris e Hyphessobrycon bifasciatus. Os grupos com maior ocorrência ao longo da bacia do Peruípe foram Siluriformes $(38,5 \%)$ e Characiformes (34,6\%). A abundância relativa de Characiformes foi maior no terço superior da bacia (50\%), enquanto que a de Siluriformes no mesmo trecho foi de $31,3 \%$. Os Siluriformes predominaram ligeiramente no trecho médio (40\%), onde os Characiformes foram registrados em percentual menor (35\%). Na porção inferior da bacia voltam a dominar os Characiformes $(50 \%)$ em detrimento dos Siluriformes (20\%).

\section{Discussão}

A fauna de peixes de água doce da América do Sul, por ser composta principalmente de peixes primariamente de água doce, como os Otophysi, possui sua história evolutiva principal ligada à história geológica dos sistemas hídricos no continente (Castro 1999). O Leste do Brasil é uma região com reconhecido endemismo para peixes de água doce na América do Sul (Menezes 1972, Menezes 1988, Weitzman et al. 1988, Bizerril 1994, Costa 1996, Buckup 1997, Menezes 1997, Rosa et al. 2003, Sarmento-Soares \& Martins-Pinheiro 2007c). Menezes (1997), baseando-se nos padrões de distribuição de espécies de Characiformes, reconheceu acentuado endemismo para a região das drenagens costeiras do Rio de Janeiro ao sul da Bahia, denominando a área geográfica de região costeira norte. Três espécies capturadas no Rio Peruípe ocorrem em bacias costeiras entre o Rio Paraíba do Sul e o sul da Bahia: Otothyris travassosi, Parauchenipterus striatulus e Crenicichla lacustris, e se encaixam na definição proposta por Menezes (1997). Uma situação de endemismo regional é observada na ictiofauna do Rio Peruípe por Oligosarcus acutirostris e Aspidoras virgulatus. Essas espécies são endêmicas de drenagens costeiras entre o norte do Espírito Santo e o extremo sul da Bahia. Outras espécies de peixes possuem distribuição similar, como Rachoviscus graciliceps, conforme reportado por Sarmento-Soares \& Martins-Pinheiro (2006), Mimagoniates sylvicola reportado por 
Tabela 5. Pontos de coleta históricos na bacia do Rio Peruípe.

Table 5. Historical records for the Rio Peruípe basin.

\begin{tabular}{|c|c|c|c|c|c|}
\hline Coleta & Data & Ponto & Localidade & Município & Fonte \\
\hline H01 & - & MNZ1446 & - & Caravelas & NEODAT \\
\hline $\mathrm{H} 02$ & $1 / 01 / 79$ & MNDFM00000001 & $\begin{array}{l}\text { Recife das Caboclas + Areia + Aranguera estuário do rio } \\
\text { Caravelas }\end{array}$ & Caravelas & NEODAT \\
\hline $\mathrm{H} 03$ & $1 / 01 / 79$ & MNDFM00000009 & Recife de Viçosa & Nova Viçosa & NEODAT \\
\hline $\mathrm{H} 04$ & $1 / 01 / 79$ & MNDFM00000013 & Coroa Vermelha, de Nova Viçosa & Nova Viçosa & NEODAT \\
\hline $\mathrm{H} 05$ & $18 / 08 / 93$ & MNPSY93081801 & Poça de Maré, no topo do recife, Recife de Viçosa, BA & Nova Viçosa & \\
\hline H06 & 21/08/94 & MNGF94082101 & Poça de Maré, Recife de Viçosa, BA & Nova Viçosa & NEODAT \\
\hline H07 & 23/08/94 & MNGF94082301 & Poça de Maré, Recife de Viçosa, BA & Nova Viçosa & NEODAT \\
\hline H08 & $23 / 01 / 95$ & MNGWN95012302 & $\begin{array}{l}\text { Topo do recife, recife Coroa Vermelha ao largo de Nova } \\
\text { Viçosa, BA }\end{array}$ & Nova Viçosa & NEODAT \\
\hline H09 & $25 / 01 / 95$ & $\begin{array}{l}\text { MCSAS9523B } \\
\text { MZSAS9523B }\end{array}$ & $\begin{array}{l}\text { Arroio afluente do rio Peruipe na estrada entre a BR-101 e } \\
\text { Caravelas, cerca de } 14 \mathrm{~km} \text { a oeste da BR-101. }\end{array}$ & Caravelas & NEODAT \\
\hline $\mathrm{H} 10$ & $25 / 01 / 95$ & $\begin{array}{l}\text { MCSAS9524B } \\
\text { MZSAS9524B }\end{array}$ & $\begin{array}{l}\text { Córrego Pau Alto (afl. do rio Pau Alto), na estrada BR- } 418 \text {, } \\
\text { cerca de } 58 \mathrm{~km} \text { a leste de Nanuque. }\end{array}$ & Caravelas & NEODAT \\
\hline H11 & 25/01/95 & $\begin{array}{l}\text { MCSAS9534A } \\
\text { MZSAS9534A }\end{array}$ & $\begin{array}{l}\text { Rio do Meio junto à estrada BR-101, cerca de } 28 \mathrm{~km} \text { ao Sul } \\
\text { de Teixeira de Freitas. }\end{array}$ & $\begin{array}{l}\text { Teixeira de } \\
\text { Freitas }\end{array}$ & NEODAT \\
\hline H12 & $3 / 02 / 95$ & MNGWN95020301 & Região estuarina, frontal ao mun. Nova Viçosa, BA & Nova Viçosa & NEODAT \\
\hline H13 & $29 / 08 / 95$ & MNPSY95082901 & Recife de Viçosa, Nova Viçosa, Bahia. & Nova Viçosa & \\
\hline H14 & $1 / 01 / 97$ & MZRLO97010002 & $\begin{array}{l}\text { Estuário e boca do Rio Caravelas. Entre o continente e o Ar- } \\
\text { quipélago dos Abrolhos. }\end{array}$ & Caravelas & NEODAT \\
\hline H15 & 2/06/97 & MZALA97060201 & Rio Peruípe, porto de Nova Viçosa. & Nova Viçosa & \\
\hline H16 & $15 / 11 / 98$ & EC 24 & $\begin{array}{l}\text { Três km ao leste da ponte na estrada entre Caravelas e Nova } \\
\text { Viçosa. }\end{array}$ & Caravelas & $\begin{array}{l}\text { MMA/SRH } \\
1999\end{array}$ \\
\hline H17 & $16 / 11 / 98$ & EC 25 & Dois km ao oeste da ponte na estrada BR101 & Caravelas & $\begin{array}{l}\text { MMA/SRH } \\
1999\end{array}$ \\
\hline $\mathrm{H} 18$ & 31/03/99 & MZRLO99033101 & Manguezal de Caravelas & Caravelas & NEODAT \\
\hline
\end{tabular}

Menezes \& Weitzman (1990) e Pseudauchenipterus affinis reportado por Sarmento-Soares \& Martins-Pinheiro (2007c). Dentre as espécies capturadas na bacia do Peruípe, duas tem endemismo para bacias do extremo sul da Bahia: Trichomycterus pradensis e Microglanis pataxo (Sarmento-Soares et al. 2005 e 2006).

Elementos da ictiofauna com influência marinha são representados por Microphis brachyurus, Awaous tajasica e Trinectes paulistanus, que são espécies com distribuição ampla pela costa brasileira pelo menos até Santa Catarina, e não contribuem na elucidação de padrões de endemismo para as espécies na região. Espécies marinhas que penetram o curso inferior dos rios costeiros não foram relacionadas no presente estudo.

$\mathrm{Na}$ ausência de nomes disponíveis para as drenagens naquele trecho do litoral, e em vista da pequena diferença morfológica observada, Astyanax cf. lacustris, Astyanax cf. rivularis, Imparfinis cf. minutus e Pimelodella cf. vittata foram identificadas baseando-se nos nomes de espécies na drenagem do Rio das Velhas, sendo consideradas diferenciadas das populações do Alto São Francisco, Minas Gerais. Poucas espécies têm distribuição comum ao alto Rio São Francisco e drenagens litorâneas do Espírito Santo e sul da Bahia, a exemplo Cyphocharax gilbert segundo Vari (1992) e Glanidium albescens segundo Sarmento-Soares e Martins-Pinheiro (2007c). Duas espécies presentes no Peruípe ocorrem em rios costeiros de Mata Atlântica, como Mimagoniates microlepis e Scleromystax prionotos.

O encontro de novas espécies na região de estudo indica a importância de se desenvolver trabalhos de campo em regiões pouco exploradas do ponto de vista ictiológico. A maior representatividade de espécies ficou com as ordens Siluriformes e Characiformes, que juntas correspondem a pouco mais de $70 \%$ das espécies capturadas na bacia. O elevado percentual de peixes das ordens Siluriformes e Characiformes na bacia do Peruípe está de acordo com a composição da ictiofauna esperada para rios neotropicais (Lowe-McConnell 1999). A maior representatividade de Siluriformes e Characiformes em sistemas fluviais de Mata Atlântica é reportada por outros autores (p. ex., Mazzoni 1998, Castro 1999, Serra et al. 2007). Espécies assinaladas com "status" taxonômico indefinido como Characidium sp., Rhamdia sp. e Hypostomus sp. podem representar novos táxons no âmbito de trabalhos de revisão.

Castro (1999) e Castro et al. (2003) ressaltam que o pequeno tamanho, inferior a $150 \mathrm{~mm}$, permite aos peixes de riacho a ocupação de micro-ambientes bastante específicos, e que as espécies tendem a completar seus ciclos de vida em áreas geograficamente limitadas, sugerindo acentuado endemismo. No Rio Peruípe as espécies capturadas não excederam $150 \mathrm{~mm} \mathrm{CP}$, e as menores espécies apresentaram tamanho adulto inferior a $50 \mathrm{~mm} \mathrm{CP}$.

A dinâmica dos rios que atravessam os tabuleiros costeiros, no nordeste do Brasil, é significativamente diferente dos riachos costeiros de Floresta Atlântica na Serra do Mar, no Sudeste do Brasil, onde os rios descem de encostas de altas montanhas. No tabuleiro não há grandes elevações, a declividade é baixa e os ambientes de corredeira, tão característicos das encostas serranas, são bastante raros. Muitos 
Tabela 6. Lista taxonômica das espécies de peixes na foz do Rio Peruípe (Delta do Caravelas), conforme registros históricos, obtidos a partir do banco de dados do projeto NEODAT e Relatório MMA/SRH 1999.

Table 6. Taxonomic list of species on mouth of Rio Peruípe (Delta of rio Caravelas), according to historical records, obtained through the NEODAT project database and MMA/SRH 1999 report.

CHONDRICHTHYES

Charcharhiniformes

Carcharhinidae

Rhizoprionodon lalandei (Müller \& Henle, 1839)

Rajiformes

Dasyatidae

Dasyatis guttata (Bloch \& Schneider, 1801)

Myliobatidae

Gymnura micrura (Bloch \& Schneider, 1801)

\section{ACTINOPTERYGII}

Anguilliformes

Ophichtidae

Myrophis punctatus Lütken, 1851

\section{Clupeiformes}

Engraulidae

Anchoa spinifera (Valencienes, 1848)

Anchovia clupeoides (Swainson, 1839)

Anchoviella lepidentostole (Fowler, 1941)

Cetengraulis edentulus (Cuvier, 1829)

Lycengraulis grossidens (Agassis, 1829)

Pristigasteridae

Chirocentrodon bleekerianus (Poey, 1867)

Odontognathus mucronathus Lacépède, 1800

Pellona harroweri (Fowler, 1919)

Clupeidae

Opisthonema oglinum (Lesueur, 1818)

Platanichthys platana (Regan, 1917)

\section{Siluriformes}

Ariidae

Aspistor luniscutis (Valenciennes, 1840)

Bagre bagre (Linnaeus, 1758)

Bagre marinus (Mitchill,1815)

Cathorops sp.

Genidens genidens (Miranda Ribeiro, 1918)

Notarius grandicassis (Valenciennes, 1840)

\section{Batrachoidiformes}

Batrachoididae

Thalassophryne punctata Steindachner, 1876

\section{Lophiiformes}

Ogcocephalidae

Ogcocephalus vespertilio (Linnaeus, 1758)

\section{Mugiliformes}

Mugilidae

Mugil curema Valenciennes, 1836

\section{Beloniformes}

Hemiramphidae

Hyporhamphus unifasciatus (Ranzani, 1842)

\section{Beryciformes}

Holocentridae

Holocentrus ascensionis (Osbeck, 1765)

\section{Gasterosteiformes}

Syngnathidae
Microphis brachyurus (Bleeker, 1853)

\section{Scorpaeniformes}

Scorpaenidae

Scorpaena plumieri Bloch, 1789

Trigllidae

Prionotus punctatus (Bloch, 1793)

\section{Perciforme}

Carangidae

Caranx hippos (Linnaeus, 1766)

Caranx latus Agassis, 1831

Chloroscombrus chrysurus (Linnaeus, 1766)

Oligoplites palometa (Cuvier, 1832)

Selene vomer (Linnaeus, 1758)

Lutjanidae

Lutjanus analis (Cuvier, 1828)

Lutjanus jocu (Bloch \& Schneider, 1801)

Gerreidae

Eucinostomus havana (Nichols, 1912)

Eugerres brasilianus (Valencienes, 1830)

Haemulidae

Conodon nobilis (Linnaeus, 1758)

Genyatremus luteus (Bloch, 1795)

Haemulon aurolineatum (Cuvier, 1830)

Haemulon parra (Desmarest, 1823)

Haemulon plumieri (Lacépède, 1812)

Pomadasys corvinaeformis (Steindachner, 1868)

Pomacentridae

Abudefduf saxatilis (Linnaeus, 1758)

Sciaenidae

Bairdiella ronchus (Cuvier, 1830)

Ctenosciaena gracillicirhus (Metzclaar, 1919)

Cynoscion leiarchus (Cuvier, 1830)

Cynoscion microlepidotus (Cuvier, 1830)

Isopisthus parvipinnis (Cuvier, 1830)

Larimus breviceps Cuvier, 1830

Menticirrhus americanus (Linnaeus, 1758)

Menticirrhus littoralis (Holbrook, 1847)

Paralonchurus brasiliensis (Steindachner, 1875)

Stellifer brasiliensis (Schultz, 1945)

Stellifer rastrifer (Jordan, 1889)

Pomacentridae

Halichoeres poeyi (Steindachner, 1867)

Stegastes fuscus (Cuvier, 1830)

Scaridae

Scarus coelestinus Valenciennes, 1840

Sparisoma rubripinne (Valenciennes, 1840)

Labrisomidae

Paraclinus arcanus Guimarães \& Bacellar, 2002

Paraclinus nigripinnis (Steindachner, 1867)

Gobiidae

Awaous tajasica (Lichtenstein, 1822)

Bathygobios soporator (Valenciennes, 1837) 
Tabela 6. Continuação...

Ctenogobius boleosoma (Jordan and Gilbert, 1882)

Ctenogobius smaragdus (Valenciennes, 1837)

Ephippidae

Chaetodipterus faber (Broussonet, 1782)

Scombridae

Scomberomorus brasiliensis Collete, Russo \& ZavalaCamin, 1978

Stromateidae

Peprilus paru Linneaus, 1758

\section{Pleroneuctiformes}

Paralichthyidae

Paralichthys brasiliensis (Ranzani, 1842)

Achiridae

Achirus declivis Chabanaud, 1940

Achirus lineatus (Linnaeus, 1758)

Cynoglossidae

Symphurus tessellatus Quoy \& Gaimard, 1824)

\section{Tetraodontiformes}

Balistidae

Balistes vetula Linnaeus, 1758

Tetraodontidae

Lagocephalus laevigatus (Linnaeus, 1766)

Sphoeroides testudineus (Linnaeus, 1758) rios da bacia do Peruípe nascem em lagoas, e contribuem para formar uma extensa malha de pequenos riachos ao longo de toda a bacia.

Os eventos de desmatamento e perda da mata ciliar no vale do Peruípe são relativamente recentes, menos de 50 anos, mas sua influência já aparece sobre a ictiofauna na bacia. Nas localidades onde a cobertura vegetal foi removida, o leito do rio apresentou-se assoreado, e não foram registrados muitos potenciais locais de abrigo e alimentação. A interação entre a mata ciliar e o canal do rio fornece diferentes hábitats aquáticos, fornecendo abrigo e servindo como locais para alimentação e reprodução (Cowx \& Welcomme 1998, Cetra 2003). Na bacia do Peruípe os ambientes alterados antropicamente foram encontrados principalmente no terço superior da bacia, onde predominaram trechos com intenso assoreamento, perda da mata ciliar e incidência direta da luz solar sobre o rio. Tais locais alterados não propiciam ambientes para certas espécies, e apenas as mais adaptadas a essas condições sobrevivem. Localidades como o Ponto 1 tiveram uma dominância de espécies oportunistas, como Geophagus brasiliensis e Poecilia vivipara, que resistem às condições de insolação direta e sobrevivem à substituição da vegetação marginal por pasto. De acordo com Knoppel (1970), espécies oportunistas apresentam plasticidade trófica e são capazes de utilizar recursos alimentares em condições adversas. As espécies de peixes encontradas no Ponto 1 são capazes de se aproveitar dos recursos disponíveis em ambientes pobres. Por outro lado, algumas espécies de peixes de pequeno porte dependem da vegetação marginal para alimentação, como é o caso de Mimagoniates microlepis, conforme Mazzoni \& Iglesias-Rios (2002). Espécies de peixes historicamente registradas para o Rio Peruípe,

Tabela 7. Classificação das espécies coletadas na bacia do Rio Peruípe por ponto amostrado e de acordo com a constância de ocorrência.

Table 7. Classification of sampled species along the Rio Peruípe basin by collecting locality and according to constancy of occurrence.

\begin{tabular}{|c|c|c|c|}
\hline Espécie & Pontos amostrados & Constância de ocorrência (\%) & Categoria \\
\hline Geophagus brasiliensis & 9 & 82 & constantes \\
\hline Hoplias malabaricus & 7 & 64 & constantes \\
\hline Astyanax cf. rivularis & 6 & 55 & constantes \\
\hline Poecilia vivipara & 6 & 55 & constantes \\
\hline Astyanax cf. lacustris & 5 & 45 & acessórias \\
\hline Hyphessobrycon bifasciatus & 5 & 45 & acessórias \\
\hline Scleromystax prionotos & 4 & 36 & acessórias \\
\hline Otothyris travassosi & 4 & 36 & acessórias \\
\hline Oligosarcus acutirostris & 3 & 27 & acessórias \\
\hline Tetragonopterus cf. chalceus & 3 & 27 & acessórias \\
\hline Pimelodella cf. vittata & 3 & 27 & acessórias \\
\hline Microglanis pataxo & 3 & 27 & acessórias \\
\hline Parauchenipterus striatulus & 3 & 27 & acessórias \\
\hline Characidium sp. & 2 & 18 & ocasionais \\
\hline Imparfinis cf. minutus & 2 & 18 & ocasionais \\
\hline Rhamdia sp. & 2 & 18 & ocasionais \\
\hline Australoheros sp. & 2 & 18 & ocasionais \\
\hline Trinectes paulistanus & 2 & 18 & ocasionais \\
\hline Mimagoniates microlepis & 1 & 9 & ocasionais \\
\hline Hoplerythrinus unitaeniatus & 1 & 9 & ocasionais \\
\hline Trichomycterus pradensis & 1 & 9 & ocasionais \\
\hline Aspidoras virgulatus & 1 & 9 & ocasionais \\
\hline Hypostomus sp. & 1 & 9 & ocasionais \\
\hline Phalloceros sp. & 1 & 9 & ocasionais \\
\hline Synbranchus marmoratus & 1 & 9 & ocasionais \\
\hline Crenicichla lacustris & 1 & 9 & ocasionais \\
\hline
\end{tabular}


Tabela 8. Estimativas de riqueza de espécies de peixes de água doce na Bacia do Rio Peruípe.

Table 8. Estimation on freshwater fish species richness along the Rio Peruípe basin.

\begin{tabular}{lllll}
\hline \multicolumn{1}{c}{ Estimadores } & Alto & Médio & Baixo & Bacia \\
\hline Chao 2 & 22,4 & 21,9 & 19,8 & 30,8 \\
Jackknife 1 & 20,3 & 25,6 & 14,0 & 33,3 \\
Jackknife 2 & 23,1 & 25,3 & 14,0 & 36,1 \\
Bootstrap & 17,4 & 23,1 & 12,0 & 29,5 \\
Número de espécies coletadas & 15 & 20 & 10 & 26 \\
\hline
\end{tabular}

Tabela 9. Descritores da ictiofauna: índices de dominância, diversidade e equitabilidade na bacia do Rio Peruípe.

Table 9. Descriptors of the ichthyofauna: dominancy, diversity and equitability indexes on the Rio Peruípe basin.

\begin{tabular}{lllll}
\hline \multicolumn{1}{c}{ Descritores } & \multicolumn{1}{c}{ Alto } & Médio & Baixo & Bacia \\
\hline $\begin{array}{l}\text { Número de } \\
\text { espécies }\end{array}$ & 15 & 20 & 9 & 26 \\
$\begin{array}{l}\text { Número de } \\
\text { exemplares }\end{array}$ & 280 & 265 & 131 & 676 \\
$\begin{array}{l}\text { Dominância D } \\
\text { Diversidade H }\end{array}$ & 0,1859 & 0,115 & 0,313 & 0,08999 \\
Equitabilidade E & 0,125 & 2,396 & 1,443 & 2,644 \\
\hline
\end{tabular}

como Moenkhausia doceana (citada em MMA/SRH 1999 e no banco de dados do projeto NEODAT 2007), não foram capturadas durante o período de amostragem. Cetra (2003) indicou, para um ambiente fluvial na bacia do Tietê, em São Paulo, que as assembléias de peixes sofrem influência de fatores extrínsecos representados por variáveis ambientais. É possível que a perda da mata ciliar tenha influenciado na ocorrência e distribuição de algumas espécies ao longo da bacia do Rio Peruípe, o que pode ter contribuído para o não aparecimento de Moenkhausia doceana durante as amostragens. A perda de microhábitats característicos de áreas vegetadas e a incidência solar direta representam fatores críticos à sobrevivência de determinadas espécies. A grande riqueza de espécies em alguns locais no terço médio/baixo do Rio Peruípe (Pontos 6, 8 e 10) estaria associada à maior variedade de ambientes, e presença de mata ciliar. A associação entre riqueza de espécies e uma alta heterogeneidade de hábitats foi ressaltada por Peres Neto et al. (1995) para um rio costeiro no Rio de Janeiro. Casatti (2005) observou um aumento da riqueza de espécies no gradiente longitudinal associando a um progressivo acréscimo na diversidade de micro-hábitats em um riacho de uma reserva florestal no sudeste do Brasil. Na bacia do Peruípe constatou-se que a riqueza de espécies foi maior no terço médio e menor nos trechos à montante e à jusante, o que não corresponde à tendência natural de um rio neotropical, onde a riqueza de espécies tende a aumentar da cabeceira em direção a foz (Garutti 1988, Bennemann et al. 1995, Casatti 2005). Conforme a teoria do Rio Contínuo de Vannote et al. (1980), o contínuo longitudinal pode ser artificialmente fragmentado em trechos de rio, em virtude, por exemplo, de alterações nos hábitats naturais. Tal fragmentação pode ocasionar modificações nos padrões de distribuição das assembléias de peixes (Teixeira et al. 2005). Vieira \& Shibatta (2007) registraram maior riqueza de espécies no trecho intermediário e menor nos trecho à montante e à jusante, em um riacho urbano antropicamente alterado no sul do Brasil. No caso do Rio Peruípe não foram consideradas as espécies marinhas e estuarinas encontradas no grande delta do rio, o que seguramente garantiria uma riqueza maior na foz. A ictiofauna no vale do Peruípe vem sendo gradativamente alterada por atividades humanas, como desmatamento ciliar, o represamento de córregos e principalmente a retificação dos riachos na região das nascentes. É óbvia a necessidade premente de programas de recuperação ambiental ao longo do vale, em especial na região das nascentes, mas esta necessidade se faz presente em grande parte do território nacional. Sabemos que as espécies não se distribuem aleatoriamente. Diversos fatores históricos e ambientais determinam estes limites de distribuições. A busca dos fatores determinantes da distribuição é de grande importância, pois permitem a construção de modelos preditivos. Dispomos atualmente de uma ampla gama de métodos para estabelecimento dos padrões de distribuição. Nenhum destes métodos por si só poderá nos dar todas as respostas que a complexidade multidimensional da construção da biodiversidade demanda. As áreas geográficas são sistemas abertos e têm histórias múltiplas e complicadas, de modo que não há como explicar de uma maneira simples os padrões biogeográficos (Funk 2004). Os métodos históricos são os que permitem elucidar as conexões pretéritas entre as áreas e desta forma nos dar uma explicação da existência dos padrões de distribuição de uma determinada área. Mas muitas vezes o que nos interessa são estes padrões em si e não suas explicações. Os métodos históricos não levam em conta a ecologia das espécies (Cerqueira 1995) que tem grande importância na identificação dos padrões de distribuição regionais. No caso específico das espécies de água doce, elas estão sujeitas às variações muito significativas por fenômenos recentes que não podem ser determinados por padrões históricos. Na região de estudo, por exemplo, o forte desmatamento ocorrido e a destruição quase completa da mata ciliar nos últimos 30 a 50 anos têm uma influência na distribuição da fauna de água doce, com possibilidades inclusive de ter provocado extinções locais. Tal influência só poderá ser detectada por métodos que considerem os diversos valores ecológicos envolvidos.

\section{Agradecimentos}

Queremos deixar nossos agradecimentos aos colegas do Setor de Ictiologia do Museu Nacional/UFRJ, especialmente a Gustavo W. Nunan, Paulo A. Buckup e Priscilla Mota. Aos colegas Arion Túlio Aranda e Carine Cavalcante Chamon pelo empenho e ajuda durante os trabalhos de campo. A Marcelo R. Britto pela identificação dos Callichthyidae. A Paulo H.F. Lucinda pela identificação de Phalloceros. Somos gratos a Benevaldo Guilherme Nunes pela ajuda e incentivo para publicação. Financiamento para os trabalhos de campo foi dado pelo All Catfish Species Inventory (http://clade.acnatsci.org/allcatfish), com fundos da National Science Foundation, USA, NSF DEB-0315963. Somos gratos ao apoio da UFRJ/ MNRJ (Universidade Federal do Rio de Janeiro/Museu Nacional), pelo veículo utilizado para transporte durante os trabalhos de campo. Agradecemos ao Instituto Brasileiro do Meio Ambiente e dos Recursos Naturais Renováveis (IBAMA) pela licença de coleta regional para a área de estudo. Aos pescadores dos rios do vale do Peruípe, em especial a Totó e a Meire, que colaboraram efetivamente para nossas amostragens cedendo peixes inclusive para fotografia. Ao povo da vila de Cumuruxatiba, Prado, pela hospitalidade, incentivo e apoio para realização de nosso trabalho com os peixes do Extremo Sul da Bahia. A autora principal recebeu financiamento parcial através de bolsa de pós-doutorado sênior pelo CNPq (processo nº 154358/2006-1).

\section{Referências Bibliográficas}

ALBUQUERQUE, L. 1987. Viagens ao Brasil nos primeiros anos do século XVI. In Crônicas de história de Portugal, Presença, Lisboa, p. 60-63.

BENNEMANN, S.T., SILVA-SOUZA, A.T. \& ROCHA, G.R.A. 1995. Composición ictiofaunistica em cinco localidades de la cuenca del rio Tibagi, PR - Brasil. Interciencia 20:7-13. 
BIZERRIL, C.R.S.F.A. 1994. Análise taxonômica e biogeográfica da ictiofauna de água doce do leste brasileiro. Acta Biol. Leopoldensia 16:51-80.

BUCKUP, P.A. 1997. Biodiversidade dos peixes da Mata Atlântica. In Workshop Padrões de Distribuição da Diversidade da Mata Atlântica do Sul e Sudeste Brasileiro, 1997, Campinas. Workshop Padrões de Distribuição da Diversidade da Mata Atlântica do Sul e Sudeste Brasileiro, 1996.

BUCKUP, P.A., MENEZES, N.A. \& GHAZZI, M.S. (eds.). 2007. Catálogo das espécies de peixes de água doce do Brasil. Série livros 23. Museu Nacional. Universidade Federal do Rio de Janeiro, Rio de Janeiro.

CARVALHO-FILHO, A. 1999. Peixes: costa brasileira. 3a. edição, Ed. Melro, São Paulo.

CASATTI, L. 2005. Fish assemblage structure in a first order stream, southeastern Brazil: longitudinal distribution, seasonality, and microhabitat diversity. Biota Neotrop. 5(1):http://www.biotaneotropica. org.br/v5n1/pt/abstract?article+BN02505012005

CASTRO, R.M.C. 1999. Evolução da ictiofauna de riachos sul-americanos: padrões gerais e possíveis processos causais. In Ecologia de peixes de riachos: estado atual e perspectivas (E.P. Caramaschi, R. Mazzoni, C.R.S.F. Bizerril \& P.R. Peres-Neto, eds.), Oecologia Brasiliensis, vol. VII, Rio de Janeiro, p. 139-155.

CASTRO, R.M.C., CASATTI, L., SANTOS, H.F., FERREIRA, K.M., RIBEIRO, A.C., BENINE, R.C., DARDIS, G.Z.P., MELO, A.L.A., STOPIGLIA, R., ABREU, T.X., BOCKMANN, F.A., CARVALHO, M., GIBRAN, F.Z. \& LIMA, F.C.T. 2003. Estrutura e composição da ictiofauna de riachos do rio Paranapanema, sudeste e sul do Brasil. Biota Neotrop. 3(1):http://www.biotaneotropica.org.br/v3n1/pt/ abstract?article+BN01703012003

CERQUEIRA, R. 1995. Determinação de distribuições potenciais de espécies. In Tópicos em Tratamento de Dados Biológicos (P. Peres-Neto, J.L. Valentin \& F.A.S. Fernandes, eds.). Oecologia Brasiliensis, v. II, Rio de Janeiro, p. 141-161

CETRA, M. 2003. Caracterização das assembléias de peixes da bacia do rio Corumbataí (SP). Tese de Doutorado não publicada. Universidade de São Paulo. Escola de Engenharia de São Carlos, Ciências da Engenharia Ambiental, São Paulo.

CHAGAS, P.P. 1978. Teófilo Otoni. Ministro do Povo. 3a ed. Itatiaia, Belo Horizonte.

COLWELL, R.K., \& CODDINGTON, J.A. 1994. Estimating terrestrial biodiversity through extrapolation. Philos. Trans. R. Soc. London [Biol.] 345:101-118.

COLWELL, R.K., MAO, C.X. \& CHANG, J. 2004. Interpolating, extrapolating, and comparing incidence-based species accumulation curves. Ecology 85:2717-2727

COSTA, W.J.E.M. 1996. Phylogenetic and biogeographic analysis of the Neotropical annual fish genus Simpsonichthys (Cyprinodontiformes: Rivulidae). J. Comp. Biology 1:129-140.

COWX, L.G. \& WELCOMME, R.L. 1998. Rehabilitation of rivers for fish. Food and Agriculture Organization of the United Nations (FAO), Fishing New Books, Rome.

CRA (CENTRO DE RECURSOS AMBIENTAIS). 2002. Meio ambiente de A a Z: ações do CRA entre 1999 e 2002 / Centro de Recursos Ambientais, BAHIA. SEPLANTEC, Salvador.

DAJOZ, R. 1973. Ecologia geral. Ed. Vozes, São Paulo.

DE PAULA, R.Z.A. 2005. Ocupação do espaço, formas de produção e território: uma nota sobre a formação territorial de Minas Gerais. Rev. Cient. Faminas, Muriaé 1(2):1-21.

DIAS, C.M. 1923. A Expedição de 1503. In História da colonização Portuguesa do Brasil, vol. II - A Epopeia dos Litorais (C.M. DIAS, ed.). Litografia Nacional, Porto, p. 285-314.

FUNK, V.A. 2004. Revolutions in historical biogeography. In Foundations of biogeography: classic papers with commentaries (M.V. Lomolino, D.F. Sax \& J.H. Brown eds.). University of Chicago Press, Chicago and London, p. 647-657.
GARUTTI, V. 1988. Distribuição longitudinal da ictiofauna em um córrego da região noroeste do estado de São Paulo, bacia do rio Paraná. Rev. Bras. Biol. 48(4):747-759.

HAMMER, Ø., HARPER, D.A.T. \& RYAN, P.D. 2001. PAST: Palaeontological statistics software package for education and data analysis. Paleontologia Electronica 4(1):9p. http://palaeo-electronica.org/2001_1/past/issue1_01. htm.

IBGE (INSTITUTO BRASILEIRO DE GEOGRAFIA E ESTATÍSTICA). 2004. Mapa de vegetação do Brasil. Escala 1: 5.000.000. 3ª. ed. Coordenação de Recursos Naturais e Estudos Ambientais, Diretoria de Geociências, Rio de Janeiro.

KEYNES, R. 2004. Aventuras e descobertas de Darwin a bordo do Beagle. 1832-1836 (S.G. de Paula, trad.). Jorge Zahar Ed., São Paulo.

KNOPPEL, H.A. 1970. Food of central Amazonian fishes: contribution to the nutrient-ecology of Amazonian rain forest streams. Amazoniana 2:257-352.

LOWE-McCONNELL, R.H. 1999. A fauna de peixes neotropical. In Estudos ecológicos de comunidades de peixes tropicais (R.H. Lowe-McConnell, ed.). EDUSP, São Paulo, p. 129-168.

MAZZONI, R. 1998. Estrutura de comunidades e produção de peixes de um sistema fluvial costeiro de Mata Atlântica, Rio de Janeiro. Universidade Federal de São Carlos.

MAZZONI, R. \& IGLESIAS-RIOS, R. 2002. Distribution Patterns of two fish species in a coastal stream in southeast Brazil. Braz. J. Biol. 62(1):171-178.

MENEZES, N.A. 1972. Distribuição e origem da fauna de peixes de água doce das grandes bacias fluviais do Brasil. In Poluição e Piscicultura, Faculdade de Saúde Pública da Universidade de São Paulo, São Paulo, p. 73-78.

MENEZES, N.A. 1988. Implications of the distribution patterns of the species of Oligosarcus (Teolostei, Characidae) from Central and Southern South America. In Proceedings of a Workshop on Neotropical Distribution Patterns (P.E Vanzolini \& W.R. Heyer, eds.). Academia Brasileira de Ciências, Rio de Janeiro, p. 295-304.

MENEZES, N.A. 1997. Padrões de distribuição da biodiversidade da Mata Atlântica do sul e sudeste brasileiro: Peixes de Água Doce. In Workshop Padrões de Distribuição da Diversidade da Mata Atlântica do Sul e Sudeste Brasileiro, 1997, Campinas. Workshop Padrões de Distribuição da Diversidade da Mata Atlântica do Sul e Sudeste Brasileiro, 1996

MENEZES, N.A., BUCKUP, P.A., FIGUEIREDO, J.L. \& MOURA R.L. 2003. Catálogo das espécies de peixes marinhos do Brasil. Museu de Zoologia, Universidade de São Paulo, São Paulo.

MENEZES, N.A. \& WEITZMAN, S.H. 1990. Two new species of Mimagoniates (Teleostei: Characidae: Glandulocaudinae), their phylogeny and biogeography and a key to the glandulocaudin fishes of Brazil and Paraguay. Proc. Biol. Soc.Washington 103(2):380-426.

MMA/SRH (Ministério do Meio Ambiente / SECRETARIA DE RECURSOS HÍDRICOS). 1997. Plano diretor de recursos hídricos da bacia do extremo sul. Volume 6. Documento síntese. Governo do Estado da Bahia. Superintendência de Recursos Hídricos, Salvador.

MMA/SRH (Ministério do Meio Ambiente / SECRETARIA DE RECURSOS HÍDRICOS). 1999. Estudos de ictiofauna. Relatório parcial $n^{\circ} .10$ (versão definitiva). Plano Diretor de Recursos Hídricos das Bacias do Leste (rios Mucuri, São Mateus, Itanhém (Alcobaça), Peruípe, Jucuruçu e Buranhém). Fundação Arthur Bernardes, Viçosa, 77p.

NEODAT (The Inter-Institutional Database of Fish Biodiversity in the Neotropics). 2007. University of Michigan (UMMZ), the American Museum of Natural History (AMNH) and the University of New Orleans (UNO). Project funded by National Science Foundation grants (http:// www.neodat.org 03.viii.2007).

PERES-NETO, P.R., BIZERRIL, C.R.S.F. \& IGLESIAS, R. 1995. An overview of some aspects of river ecology: a case study on fish assemblages distribution in an eastern Brazilian coastal river. In Estrutura, funcionamento e manejo de ecossistemas brasileiros (F.A. Esteves, ed.). Oecologia Brasiliensis, v. I, Rio de Janeiro, p. 317-334. 
PIELOU, E.C. 1969. Association tests versus homogeneity tests: their use in subdividing quadrats into groups. Vegetation 18:4-18.

PINTO, L.M. 2004. Relatório sumário de avaliação do sistema de manejo florestal da Aracruz Celulose S/A no sul do Estado da Bahia norma de referência: NBR 14.789: 2001 - cerflor. BVQI do Brasil Sociedade Certificadora Ltda, Rio de Janeiro.

RICAN, O. \& KULLANDER, S.O. 2006. Character- and tree-based delimitation of species in the Cichlasoma' facetum group (Teleostei, Cichlidae) with the description of a new genus. J. Zool. Syst. Evol. Res. 44(2):136-152.

ROSA, R.S., MENEZES, N.A., BRITSKI, H.A., COSTA, W.J.E.M. \& GROTH, F. 2003. Diversidade, padrões de distribuição e conservação dos peixes da Caatinga. In Ecologia e Conservação da Caatinga (I.R. Leas, M. Tabarelli, J.M.C. Silva, orgs.), Editora da Universidade Federal de Pernambuco, Recife, p. 135-180.

SARMENTO-SOARES, L.M. \& MARTINS-PINHEIRO, R.F. 2006. Rachoviscus graciliceps (Characidae: Incertae Sedis) sobrevivente nos pequenos riachos do extremo sul da Bahia, Brasil. Boletim SBI 85:4-5.

SARMENTO-SOARES, L.M. \& MARTINS-PINHEIRO, R.F. 2007a. Relação do material coletado e identificado pelo Projeto Biobahia-fase 1 e 2 (http:// www.nossacasa.net/biobahia/doc/biobahia.pdf, 27.viii.2007).

SARMENTO-SOARES, L.M. \& MARTINS-PINHEIRO, R.F. 2007b. Registro de coleta do material histórico das bacias do extremo sul da Bahia (http:// www.nossacasa.net/biobahia/doc/historicas.pdf, 27.viii.2007).

SARMENTO-SOARES, L.M. \& MARTINS-PINHEIRO, R.F. 2007c. Os Auchenipteridae do leste do Brasil. Boletim SBI 87:7-8.

SARMENTO-SOARES, L.M., MARTINS-PINHEIRO, R.F., ARANDA, A.T. \& CHAMON, C.C. 2005. Trichomycterus pradensis, a new catfish from southern Bahia coastal rivers, northeastern Brazil (Siluriformes: Trichomycteridae). Ichthyol. Explor. Freshwaters 16(4):289-302.

SARMENTO-SOARES, L.M., MARTINS-PINHEIRO, R.F., CHAMON, C.C. \& ARANDA, A.T. 2006. Microglanis pataxo, a new catfish from southern Bahia coastal rivers, northeastern Brazil (Siluriformes: Pseudopimelodidae). Neotrop. Ichthyol. 4(2):157-166.

SERRA, J.P., CARVALHO, F.R. \& LANGEANI, F. 2007. Ictiofauna do rio Itatinga no Parque das Neblinas, Bertioga, Estado de São Paulo: composição e biogeografia. Biota Neotrop. 7(1):http://www. biotaneotropica.org.br/v7n1/pt/abstract?article+bn01707012007

TEIXEIRA, T.P., PINTO, B.C.T., TERRA, B.F., ESTILIANO, E.O., GRACIA, D. \& ARAÚJO, F.G. 2005. Diversidade das assembléias de peixes nas quatro unidades geográficas do rio Paraíba do Sul. Iheringia, Sér. Zool. 95(4):347-357.

VANNOTE, R. L., MINSHALL, G.W., CUMMINS, K.W., SEDELL, J.R. \& CUSHING, C.E. 1980. The river continuum concept. Can. J. Fish. Aquat. Sci.37:130-137.

VIEIRA, D.B. \& SHIBATTA, O.A. 2007. Peixes como indicadores da qualidade ambiental do ribeirão Esperança, município de Londrina, Paraná, Brasil. Biota Neotrop. 7(1):http://www.biotaneotropica.org.br/ v7n1/pt/abstract?article+bn01407012007

WEITZMAN, S.H., MENEZES, N.A. \& WEITZMAN, M.J. 1988. Phylogenetic biogeography of glandulocaudini (Teleostei: Characiformes, Characidae) with comments on the distribution off other freshwater fishes in eastern and southeastern Brazil. In Proceedings of a Workshop on Neotropical Distribution Patterns (P.E. Vanzolini \& W.R. Heyer, eds.). Acad. Bras. Ciênc., Rio de Janeiro, p. 379-427.

WIED-NEUWIED, M. de. 1940. Viagem ao Brasil. Companhia Editora Nacional, vol. 1. Coleção Brasiliana, São Paulo. 
Material das espécies de peixes coletadas ao longo da bacia do Rio Peruípe (depositadas na coleção ictiológica do MNRJ):

Aspidoras virgulatus: MNRJ 28553(1); Astyanax cf. lacustris: MNRJ 28545(20), MNRJ 28671(6), MNRJ 28681(2) e MNRJ 28686 (2); Astyanax cf. rivularis: MNRJ 28542(1), MNRJ 28548(2), MNRJ 28551(61), MNRJ 28669(58), MNRJ 28672(16) e MNRJ 28680(31); Australoheros sp.: MNRJ 29033(1) e 29103(7); Characidium sp.: MNRJ 29032(1) e MNRJ 29100(2); Crenicichla lacustris: MNRJ 29035(1); Geophagus brasiliensis: MNRJ 28301(16), MNRJ 28305(1), MNRJ 28306(5), MNRJ 28370(20), MNRJ 28371(1), MNRJ 28377 (3), MNRJ 28379 (8) e MNRJ 28390 (3); Hoplerythrinus unitaeniatus: MNRJ 28389 (1); Hoplias malabaricus: MNRJ 28300(1), MNRJ 28304(2), MNRJ 28369(1), 28372 28372(2), MNRJ 28376(4), MNRJ 28378 (6); Hyphessobrycon bifasciatus: MNRJ 28543(2), MNRJ 28552(6), MNRJ 28679 (3), MNRJ 28700 (32), MNRJ 29036(4); Hypostomus sp.: MNRJ 29101(10); Imparfinis cf. minutus: MNRJ 28533(17) e MNRJ 28549(22); Microglanis pataxo: MNRJ 28399(1 parátipo), MNRJ 28400(1 parátipo), MNRJ 28403(6 parátipos); Mimagoniates microlepis: MNRJ 28550(19); Oligosarcus acutirostris: MNRJ 28670(2), MNR 28678 (3) e MNRJ 28683(2); Otothyris travassosi: MNRJ 28539(7), MNRJ 28554(3), MNRJ 28667(15) e MNRJ 28682 (17); Phalloceros sp. B: MNRJ 28555(4); Pimellodella cf. vittata.: MNRJ 29031(8), MNRJ 29034(25), MNRJ 29104 (21); Poecilia vivipara: MNRJ 28540(3), MNRJ 28546(4), MNRJ 28668(16), MNRJ 28673(1), MNRJ 28685(4) e MNRJ 28701(22); Rhamdia sp.: MNRJ s/n(1), MNRJ s/n(2); Scleromystax prionotos: MNRJ 28702(1), MNRJ 28703(2), MNRJ 28708 (5) e MNRJ 28709(6); Synbranchus marmoratus: MNRJ 28307(1); Tetragonopterus cf. chalceus: MNRJ 28547(13), MNRJ 28684 (2) e MNRJ 28699 (37); Trachelyopterus striatulus: MNRJ 28541(2), MNRJ 28559(2) e MNRJ 28544(1); Trichomycterus pradensis: MNRJ 28485(6 parátipos); Trinectes paulistanus: MNRJ 28302(3) e MNRJ 28303(1). 